
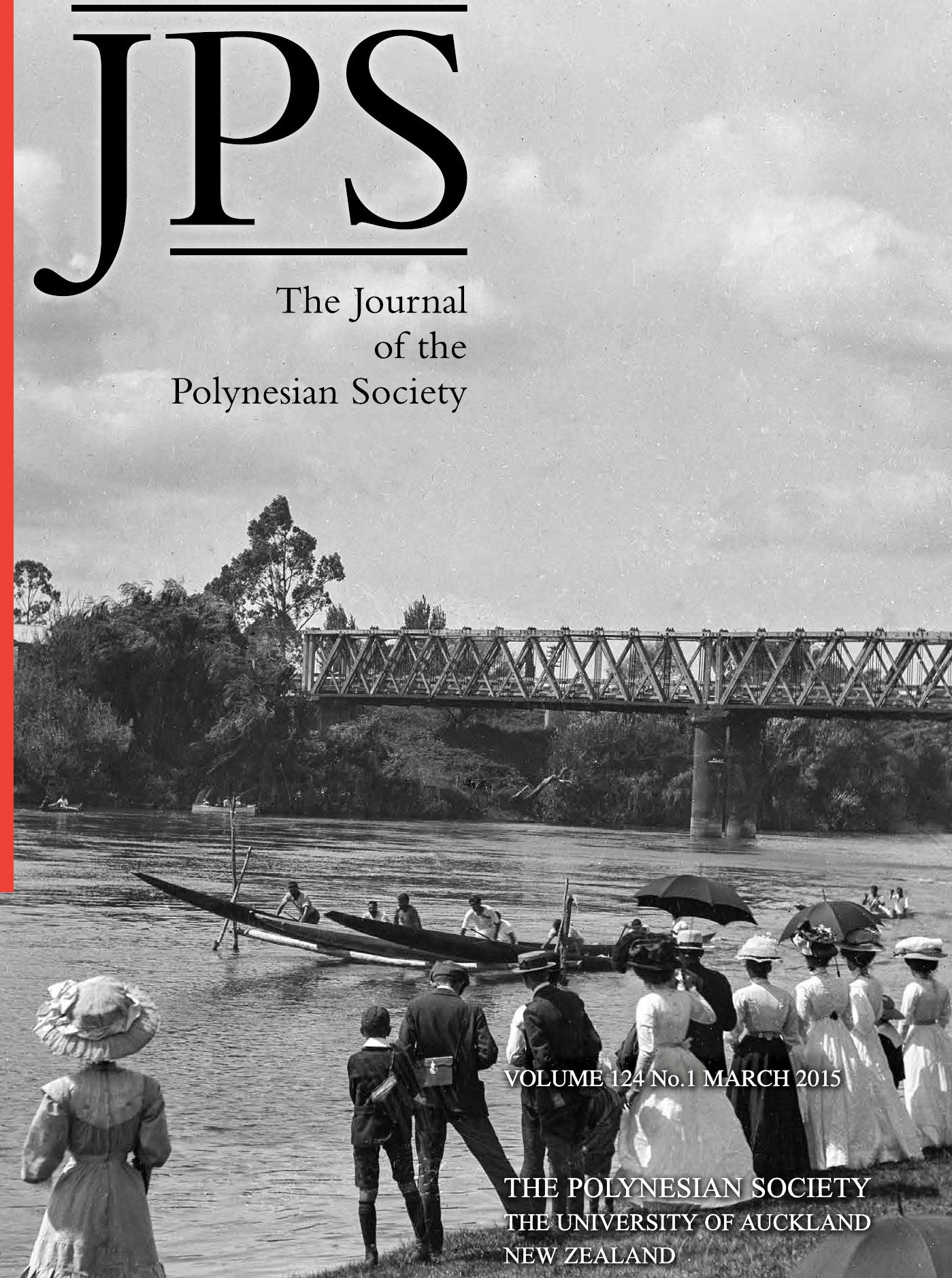


\title{
PHYLOGENETIC ANALYSIS OF POLYNESIAN RITUAL ARCHITECTURE SUGGESTS EXTENSIVE CULTURAL SHARING AND INNOVATION
}

\author{
ETHAN E. COCHRANE \\ University of Auckland
}

\begin{abstract}
That Polynesian ritual architecture (Fig. 1) displays similarities due to cultural relatedness is uncontroversial. Like many other aspects of Polynesian lifelanguage, culture, belief - there are architectural similarities across islands and archipelagos that are a product of people learning from each other, shared cultural ancestry and, perhaps less often, independent invention or convergent evolution (Kirch and Green 2001). There is also a long history of research on the cultural relatedness of Polynesian ritual architecture. In the 19th century Fornander (1969: 33-35, 59) suggested that some later Hawaiian heiau 'ritual architecture' owed their distinctive form to building techniques learned from voyagers newly arrived from the south. Later, archaeologists and anthropologists such as Emory (1933) and Linton (1925) suggested inter-archipelago interaction and ancestral connections as explanations for similarities in ritual architecture. Discussing the use of shaped, rectangular stone slabs set on end in a variety of ritual architecture, Linton outlined the evidence both for the independent invention of this construction technique throughout Polynesia, and contrastingly for its singular origin and dissemination throughout the region, "although the originating group [of islands] cannot now be determined" (Linton 1925: 19). A few years later Emory (1933: 49-50) argued that shaped stone facings found on ritual architecture in the Marquesas, Australs and Tonga likely originated in the Society Islands. Likewise, Bellwood noted that some similarities in East Polynesian marae 'ritual architecture' are a product of ancestral or phylogenetic relationships whereby:
\end{abstract}

... following a period of isolation in the Marquesas and possibly also the Society Islands, an Eastern Polynesian polythetic assemblage differing from but overlapping with the Western Polynesian spread to all remaining parts of the Polynesian triangle... [including an] open court marae with combinations of walled and/or paved enclosures, upright slabs of stone, and stone platforms (Emory 1970), together with god houses for the storage of ceremonial appurtenances. (Bellwood 1975: 15-16)

Although noting some of the same characteristics of Polynesian ritual architecture, such as the presence of shaped stones, uprights or attached 

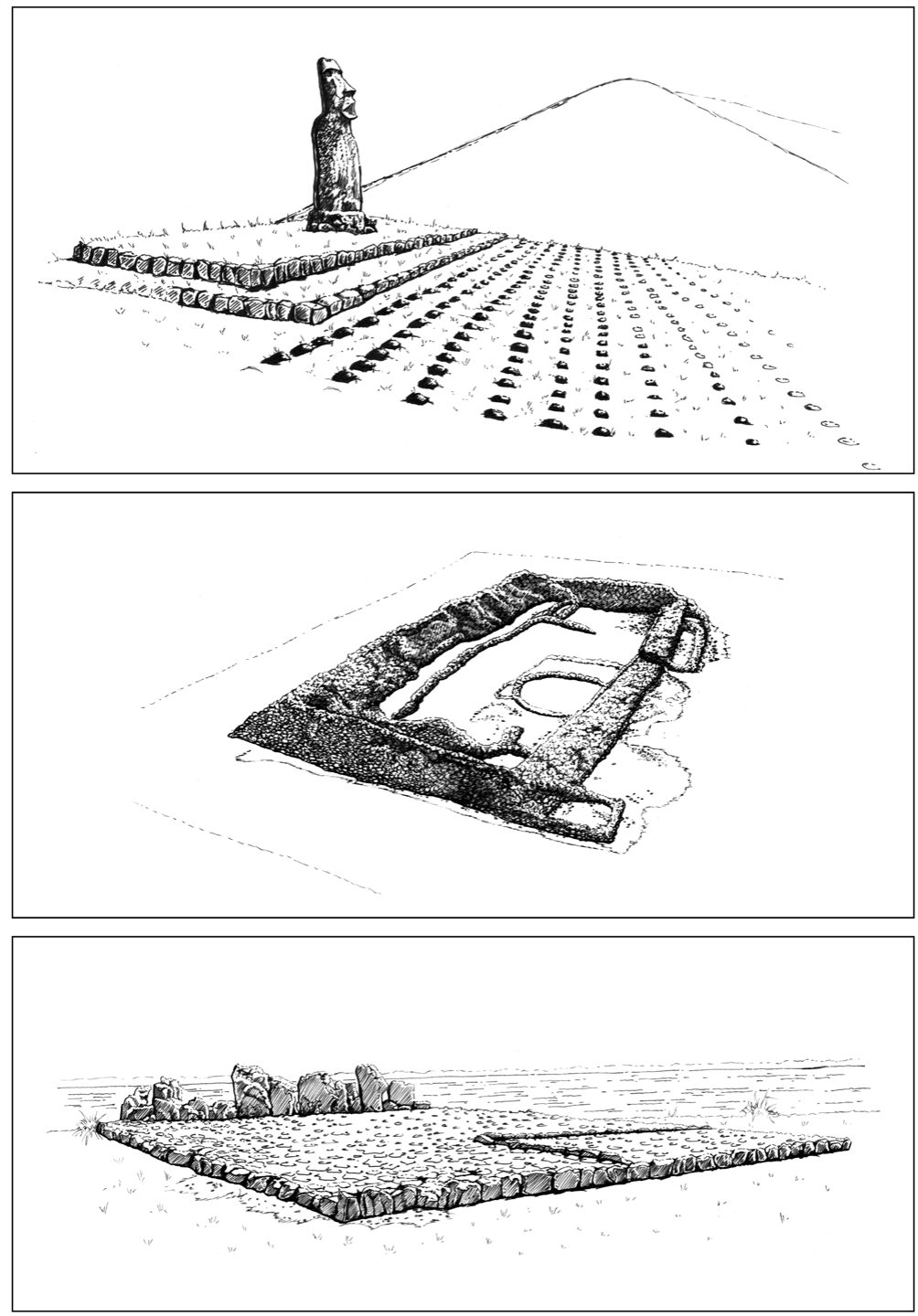

Figure 1. Polynesian ritual architecture. Top, ahu-moai Huri a Urenga, Rapa Nui (no. 174, Table 2). Middle, heiau Mo'okini, island of Hawai'i (no. 50, Table 2). Bottom, marae Vaiotaha, Huahine (no. 103, Table 2). Illustrations by Briar Sefton. 
structures, more recent analyses of marae, ahu-moai and other ritual architecture forms have interpreted similarities across structures not in terms of cultural relatedness across Polynesia, but using emic meanings of these structures. For example, Wallin (1993) examined Society Islands marae and argued that similarities (i.e., marae belonging to the same type) reflected similar ideologically charged meanings in the past, such as the rounded stones in one marae type symbolising the heads of turtles, as a proxy for humans, and the importance of human sacrifice (Wallin 1993: 101-2). Kahn and Kirch (2011) also use an emic perspective in their work on Mo'orea and argue that some marae similarities can be explained as the material manifestation of an ideology that reinforced chiefly control.

Both the more recent interpretations of Polynesian ritual architecture at an island or intra-archipelago scale (for additional examples see Kahn 2010, Kolb 1994, Martinsson-Wallin 1994, Wallin 2001) and the earlier work which examined cultural relatedness between archipelagos examine architectural similarities that are assumed to be homologous or a product of cultural transmission (cf. Kirch [1990] where some aspects of monumental or ritual architecture are considered analogous). The importance of homologous similarity when identifying cultural phylogenies has been known to archaeologists for over a century. Kirch and Green (2001; see also Lyman [2001]) provide a detailed argument for phylogenetic explanations of Polynesian cultures, including similarities in ritual architecture. To wit, the settlers of East Polynesia had previously developed a common culture over perhaps 1500 years in Samoa, Tonga and nearby islands. This ancestral Polynesian culture included:

... components of ritual architecture consistently present throughout all three main subregions of Polynesia...(1) an open space...designated by the term malae or marae; (2) some form of god house... attached or adjacent to the court...; [and] (3) posts or upright stones... (Kirch and Green 2001: 254)

Kirch and Green (2001: 89-90,276) suggest that these components of ritual architecture were carried to central East Polynesia as populations settled new island groups. Some components of ritual architecture were modified in East Polynesia and spread to multiple archipelagos, for example demarcating the malae boundaries in stone, while other innovations, such as adding monolithic anthropomorphic stone statues, had more restricted distributions.

More generally, Kirch and Green (1987, 2001; see also Kirch 1984) see phylogenetic research as necessary for a holistic historical anthropology (combining archaeology, ethnology, linguistics and bioanthropology), a goal of which is to reconstruct the cultural patterns of ancestral societies and trace the branches that diverge from them, explaining similarities and differences 
as results of adaptations to new environments, innovations, shared ancestral features, borrowings and the like. Integral to this research is the accurate reconstruction of ancestral societies for which Kirch and Green (2001: 42-52) propose a triangulation method. As survey stations are more precisely placed through measurement from multiple points, components of ancestral societies can be more precisely reconstructed if multiple lines of enquiry describe their existence. For example, comparative linguistics and ethnology both suggest the existence of ancestral Polynesian ritual architecture as described above.

The approach to analysing similarities in Polynesian monumental architecture presented here is related to Kirch and Green's phylogenetic research, but does not share the goal of reconstructing the ritual architecture components of an ancestral society. It has a simpler goal of quantitatively defining the patterns of relative phylogenetic similarity exhibited by ritual architecture and offering some possible explanatory processes for the patterns generated. In cultural phylogenetic research, patterns of similarity, such as might be depicted in a seriation order, branching tree or reticulated network, are hypotheses about patterns of cultural relatedness. By beginning with the patterns of similarity, we can evaluate the hypothesis that they are patterns of relatedness: (i) by assessing the classification used to describe the artefacts or features (for a particularly relevant example see Cochrane's [1998] assessment of Wallin's [1993] marae classification), (ii) by comparing the results of multiple pattern generation techniques (e.g., Buchanan and Collard 2008, Cochrane and Lipo 2010), and (iii) by various technique-specific support statistics (Kitching et al. 1998, and see below). If the patterns of similarity are accepted as patterns of relatedness, there are conceivably multiple processes that might explain this cultural relatedness. These include cultural trait hitchhiking (e.g., Ackland et al. 2007), natural selection and drift (e.g., Rogers and Ehrlich 2008) and population structure (e.g., Cochrane 2013); each needs to be systematically evaluated. In short, the approach taken here analyses and evaluates the generation of patterns separately from the conclusion of explanatory process (Cochrane 2001, Tolstoy 2008).

While the analysis of phylogenetic similarity has been largely developed in biology, such analyses are equally applicable to any cultural phenomena that owe some of their characteristics to transmission of information by people (Mace et al. 2005, Mesoudi 2011, Shennan 2002), including phenomena such as archaeological artefacts (e.g., Lipo et al. 2006), social trends (e.g., Bentley et al. 2004), ethnographic material culture (e.g., Tehrani and Collard 2002; also including Polynesian barkcloth, see Larsen 2011 and Tolstoy 2008), folktales (Ross et al. 2013), manuscripts (e.g., Spencer et al. 2004) and languages (e.g., Gray and Atkinson 2003). Additionally, it is important to consider that phylogenetic similarity does not denote a priori a branching 
pattern of cultural relatedness. Perhaps many misunderstand this, because the iconic representation of a biological phylogeny is a branching tree, but treelike relationships are not requisite in biology or culture. Finally, identifying phylogenetic similarities in Polynesian ritual architecture contributes to some of the fundamental research topics in Polynesian archaeology and anthropology including spatial patterns of colonisation (e.g., Wilmshurst et al. 2011), ancient interaction (McAlister et al. 2013) and the development of Polynesian ritual over time and space (e.g., Kahn and Kirch 2011).

\section{PHYLOGENETIC METHODS FOR STUDYING ARCHITECTURE}

To investigate phylogenetic similarity in the cultural realm valid techniques should be used to group similar phenomena and, perhaps more so than in biology, particular attention should be paid to how phenomena are classified. The next two sections review cladistics, a phylogenetic technique for grouping phenomena, and the classification of Polynesian ritual architecture for cladistic analysis.

\section{Cladistic Techniques}

There are multiple phylogenetic techniques for arranging classes or taxa, to use the jargon of phylogenetic analysis. Cladistics is used here, although Bayesian phylogenetics, phylogenetic networks and archaeological seriation are other options. Cladistics is a technique for arranging taxa in hierarchical sets determined by the distribution of traits across taxa. The traits that describe a taxon, such as length or colour, are termed characters in cladistics and the particular values of characters, such as $5 \mathrm{~cm}$ and blue, are character states. In this analysis, the taxa are classes of Polynesian ritual architecture and the characters describing them are particular architectural features with either presence or absence as the character state.

A common output of cladistic analysis, a branching tree, looks similar to the outputs of statistical grouping techniques such as factor analysis and hierarchical cluster analysis. Cladistics, however, is distinguished from these other techniques by the recognition of two kinds of character states, whereas statistical grouping typically considers all character states equally (when unweighted). In cladistics the two kinds of character states are ancestral and derived. Derived character states are those that two or more taxa share with their immediate common ancestor, but not with the preceding ancestor. Ancestral character states are shared by two or more taxa, their immediate common ancestor and the preceding common ancestor. Cladistic techniques find groups of taxa defined by shared derived character states. These groups or clades, should more accurately depict phylogenetic relationships than statistical grouping techniques which are based on phenetic similarity and do 
not distinguish between ancestral and derived character states (Buchannan and Collard 2008, O'Brien et al. 2001). A clade, a group of related taxa, is also called a monophyletic unit, a concept used by Kirch and Green (2001) to describe the cultures of Polynesia and their postulated ancestral culture, Ancestral Polynesian Society.

Cladistic techniques also seek to generate an optimal arrangement of taxa based on the distribution of shared derived character states and there are several different optimality algorithms depending on the criteria chosen. Here, parsimony is the optimality criterion used. Parsimony techniques attempt to group taxa in a series of hierarchical relationships such that the number of character state changes in a tree required to account for all the taxa is minimised (i.e., most parsimonious). Figure 2 depicts two cladistic trees to illustrate this point. The number of character state changes in the top tree is five, a support statistic (see above) used to evaluate competing cladistic arrangements, and also giving the length of the tree in cladistic terminology. There is one character state change for the ancestor of Taxa 2-4, one for the ancestor of Taxa 3 and 4, and there are three character state changes that occur only in Taxon 4 . We can create an alternative arrangement by switching the positions of Taxa 2 and 3 . This tree, however, contains six character state changes. Thus the top tree is considered the better hypothesis of phylogenetic relationships using the parsimony criterion.

The cladistic tree in Figure 2 is a simplified example that we would rarely find in an analysis of real data. In this tree only one character reverts to an ancestral state, the switch from B' back to B in Taxon 2 of the bottom tree. Additionally, similar character state changes do not occur across separate branches of the tree. However, with cultural data we might expect character states to sometimes revert to ancestral states, akin to a process of reinvention, and similar sequences of character state change may occur in different cultural lineages or traditions, known as homoplasy in cladistics. Given these possibilities, it is often difficult for cladistic techniques to produce a single best tree consisting only of the bifurcating splits that represent hierarchical similarity relationships. If cladistic results include multiple equally "best" trees (that is multiple trees of the same length), they may be combined into a single consensus tree which depicts only the same bifurcating splits present in each equally best tree (a strict consensus tree). However, consensus trees showing the same bifurcating splits in at least half the equally best trees (a 50 percent majority rule consensus tree) are also used to depict likely taxa relationships. Where there are contradictory taxa relationships across trees of the same length, a consensus tree depicts these relationships as unresolved, with all taxa originating from the same node.

Another way to pinpoint the best cladistic tree is to make assumptions about character state changes. Implementing models of character state change, for 

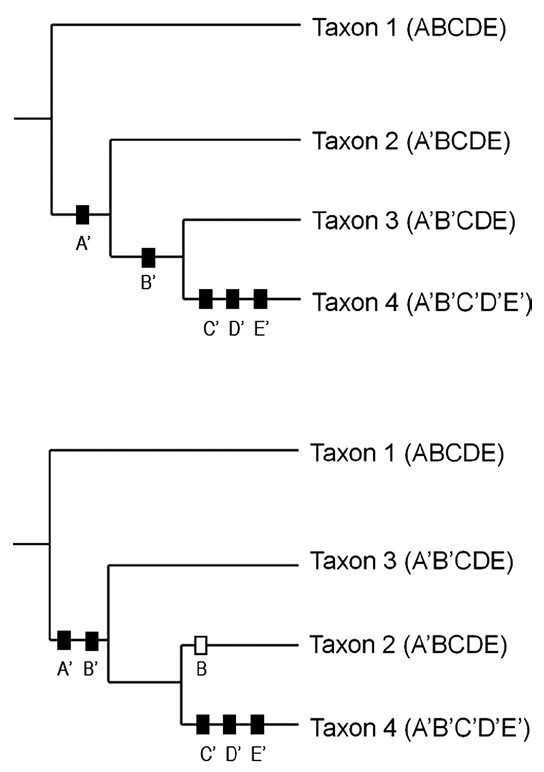

Figure 2. Two cladistic trees of Taxa 1-4 described by non-prime (ancestral) and prime (derived) character states. The top tree is the more parsimonious arrangement as only five character state changes are required as depicted by the black rectangles. On the bottom tree six character state changes are required including the reversal from B' back to the ancestral state B in Taxon 2 denoted by the open rectangle.

example deciding that change in certain characters is more likely than others or that some characters are more likely to undergo reversals than in others, may remove from consideration some trees that are otherwise in a group of equal length trees. However, this approach forces us to make additional assumptions about character state changes. Models of character state change are not inherently bad, but they do require another set of assumptions to be justified (see Tolstoy 2008).

Cladistics software takes care of the computational work of creating parsimonious trees given a dataset and there are several algorithms that can be followed to create trees, each with strengths and limitations that provide further avenues for evaluating competing arrangements. Prior to the computational work, however, researchers must construct a classification that describes taxa by homologous character states (Scotland 1992) and determine for the taxa under consideration which character states are ancestral and 
which are derived. This latter task is referred to as determining character polarity and is accomplished through the choice of an outgroup (Kitching 1992, O'Brien et al. 2002). An outgroup is a taxon related to the taxa in a cladistic tree, with the stipulation that the particular configuration of character states in the outgroup came together as a set prior to the character states in any of the taxa in the cladistic tree. Thus an outgroup determines which character states are ancestral and which are derived. As different outgroups may produce different cladistic trees given the same set of taxa, the choice of outgroup can influence cladistic results and is yet another way to evaluate cladistic results. There are different methods for determining an outgroup (Kitching 1992) but in general one should construct an outgroup taxon that is close enough to the taxa being ordered to serve as an informative guide to characters' ancestral and derived statuses.

To summarise, cladistic trees are not explanations of phylogenetic similarity among a set of taxa. A cladistic tree is one hypothesis about the pattern of phylogenetic similarity or cultural relatedness. Different trees can be generated from the same set of taxa and each of these hypotheses can be evaluated by means internal to the cladistic technique (e.g., tree support statistics, bootstrapping) and through external data such as the chronological and spatial relationships of taxa. And while cladistic techniques attempt to arrange taxa into a series of hierarchical bifurcating sets, cladogenesis or branching evolution is not the only process that may explain a cladistic arrangement of taxa. Transmission within a single cultural lineage, akin to anagenesis, or the combination of different lineages, as with hybridisation, can also explain cladistic trees of perfectly bifurcating taxa (Kimbel et al. 2006, Skala and Zrzavy 1994). The most useful way to approach a cladistic tree of cultural phenomena is to consider the arrangement a hypothesis about phylogenetic or cultural transmission-generated relatedness of the human populations that produced the artefacts and that arose through several possible processes (see Cochrane 2008: 140).

\section{Classification of Polynesian Ritual Architecture}

To analyse phylogenetic similarity of Polynesian ritual architecture, one must be able to separate the field of ritual architecture from other forms in the archaeological record (see also Rolett 2010). For the following analyses, ritual architecture is defined by a rectilinear level area, the perimeter of which is demarcated by an elevation change (e.g., a line of rocks, rock wall, earth berm) and within which there is no evidence of the range of behaviours associated with domestic activities or food production. This definition of ritual architecture does not require that every structure be excavated to confirm the 
absence of, for example, agricultural deposits or shell food remains, but it does indicate that ritual architecture identifications are hypotheses that can be evaluated in the future and that particular pieces of architecture may be added or removed based on new observations. This definition also likely excludes some pieces of architecture that should be included as their characteristics could be explained in terms of phylogenetic similarity with the ritual architecture identified here. For example, some ethnohistorically identified marae without bordered rectilinear areas (or courtyards) were not included in the structures examined. However, the purpose of defining the field as above is not to discover ethnohistorically recorded ritual locations, nor to recreate the sometimes ambiguously and idiosyncratically defined categories that are a part of our common sense (e.g., shrines, temples). The purpose is to identify pieces of architecture where there is a good chance that the similarities and differences across them are a result of cultural transmission. If, as part of the process of evaluating this research, the above definition is found to exclude some set of architecture that is likely to be phylogenetically related to the architecture analysed here, then the definition of ritual architecture can be modified, observations of the newly identified set of structures made, and the analyses re-run. Finally, the definition of ritual architecture used here is purposefully conservative to minimise errors of including architecture whose similarities are not a product of cultural transmission.

This definition of ritual architecture was applied to pieces of architecture described and identified by other researchers as presented in various publications, monographs and articles that typically focussed on local representations of ritual architecture such as marae, me 'ae and heiau (e.g., Linton 1925, Stokes and Dye 1991, Wallin 1993). Some of these previously identified pieces of architecture were not included here, principally because no rectilinear and bordered area could be identified even though other observations common to many definitions of ritual architecture, such as upright stones, could be made. Again the justification for this is to conservatively generate a set of architecture across which we can confidently expect similarities related to cultural transmission, and to which other architecture can later be added if warranted by new observations or analyses. Finally, while an attempt was made to examine the major publications dealing with ritual architecture across Polynesia (Fig. 3), hundreds of other publications (e.g., the huge cultural resource or heritage management literature in Hawai'i) might also describe stone and earth architecture that would fit the definition of ritual architecture used here. However, searching every publication was not feasible at this exploratory stage, therefore the structures used in the analyses certainly underestimate the abundance of ritual architecture in Polynesia. 


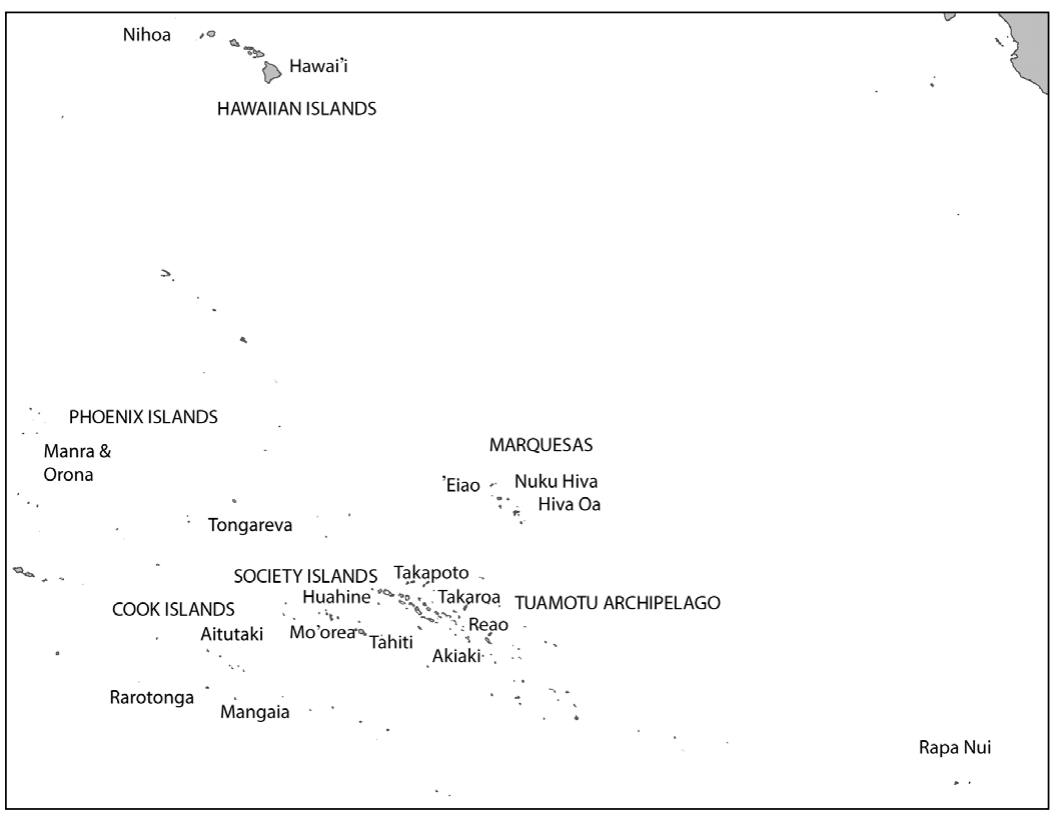

Figure 3. Map of Pacific islands, showing those islands and archipelagos (upper case) with ritual architecture used in this analysis.

After the assemblage of ritual architecture was identified, individual structures were classified. Classification for cladistics should aim to create taxa defined by characters that are homologous or demonstrate similarity due to cultural transmission. The homologous nature of characters is a hypothesis that may be discounted or confirmed with further research, but as a general guide characters should exhibit three qualities. First, they should be independent, so that the state of one character does not automatically force another character to display a particular state. If characters are not independent, the classification may generate variation related to unintended or unexamined relationships between characters, instead of variation that is explicable by transmission processes. Second, characters should not be linked to environmental variation to the degree that particular character state presences and absences may be determined by available raw materials in particular environments. For example, a character describing the use of branch coral (cf. Acropora sp.) in architecture construction would likely be 
absent in Marquesan ritual architecture, but this absence would not reflect a lack of interaction and cultural transmission (i.e., phylogenetic similarity) with, for example, Hawaiian populations, but simply the likely extirpation of branch coral in Marquesan environments over 7000 years ago (Cabioch et al. 2011). A third quality of characters used for cladistic analysis is that that their states should vary spatially and temporally. Note that character states are expected to vary temporally and spatially; this is because we expect the frequency of cultural transmission to vary across space and time, but this variation should not be a result of the differential distribution of ritual architecture raw materials, as just discussed.

Characters here were defined based on the work of previous researchers who identified aspects of Polynesian ritual architecture that changed over time or that were associated with particular islands or archipelagos. Twelve characters were defined, each with two character states, present or absent (Table 1). The characters were defined so that presence-absence states of different characters were independent, so that they did not track the availability of architectural raw materials, and so that they might vary over space and time. It is unclear how much temporal variation is generated by these characters as chronological information for the vast majority of structures is not available, but perusal of the data for each structure in Table 2 does indicate that character states vary, although some (e.g., courtyard raised) more than others (e.g., interior enclosures). Like the definition of the field of ritual architecture, the classification of that architecture can be considered a hypothesis, a hypothesis that the classes generate variation explicable by cultural-transmission processes. If subsequent analyses suggest the classes are not performing as intended, the classification can be modified. This follows Teltser's (1995) trial and error approach to classification. Considering the foregoing classification issues, it should be clear why the cladistics characters and resulting architecture classes might not conform to ethnohistorically justified or common sense categories such as luakini heiau 'war ritual architecture', national marae, or smaller-scale units such as $a h u$ 'altar'. Primarily, there are no unambiguous archaeological criteria for placing structures in these categories; there is also no theoretical warrant (see Lyman and O'Brien 2003) for using those categories to measure cultural transmission across Polynesia.

Finally, the results concerning phylogenetic similarity relate to the final forms of pieces of architecture after possible renovations to them over time. As different pieces of architecture were likely renovated to different degrees, some never and some extensively, the results must be considered a summary of phylogenetic similarity over time and space. 
Table 1. Definitions of the presence-absence characters used to classify Polynesian religious architecture.

\begin{tabular}{|c|c|}
\hline Dimension & Definition \\
\hline Courtyard Raised & $\begin{array}{l}\text { Level rectilinear surface(s) of architecture raised from } \\
\text { the ground surface on all sides }\end{array}$ \\
\hline Courtyard Walls & $\begin{array}{l}\text { Two or more courses of material are placed along any } \\
\text { portion of rectilinear boundaries of architecture, but do } \\
\text { not have to completely enclose a space }\end{array}$ \\
\hline Courtyard Paving & $\begin{array}{l}\text { Level surface(s) or architecture are paved to any extent } \\
\text { with flat material }\end{array}$ \\
\hline Multiple Courtyard Levels & $\begin{array}{l}\text { Two or more level surfaces at different elevations within } \\
\text { the boundaries of the architecture and abutting two or } \\
\text { more sides of the rectilinear boundaries of architecture }\end{array}$ \\
\hline Interior Courtyard Walls & $\begin{array}{l}\text { Two or more courses of material with a linear dimension } \\
\text { greater than vertical dimension are placed within the } \\
\text { boundaries of the architecture }\end{array}$ \\
\hline Interior Platforms & $\begin{array}{l}\text { A raised level surface within the boundaries of the } \\
\text { architecture abutting one or no sides of the rectilinear } \\
\text { boundaries of architecture }\end{array}$ \\
\hline Interior Enclosures & $\begin{array}{l}\text { Two or more courses of material are placed within the } \\
\text { boundaries of the architecture and completely enclose a } \\
\text { space }\end{array}$ \\
\hline Courtyard Pits & $\begin{array}{l}\text { An artificially excavated or modified area within the } \\
\text { boundaries of the architecture that creates a depression } \\
\text { below a level surface }\end{array}$ \\
\hline Uprights & $\begin{array}{l}\text { Single stone/coral object set freestanding in a level sur- } \\
\text { face with height greater than width }\end{array}$ \\
\hline Images & $\begin{array}{l}\text { Anthropomorphic images in stone are placed within the } \\
\text { boundaries of the architecture }\end{array}$ \\
\hline Dressed Stone or Coral & $\begin{array}{l}\text { Stone or coral used in construction modified through } \\
\text { chipping, pecking or grinding after extraction from raw } \\
\text { material source }\end{array}$ \\
\hline Substructures & $\begin{array}{l}\text { One or more enclosed spaces (raised or walled or both) } \\
\text { abut the exterior boundary of the architecture }\end{array}$ \\
\hline
\end{tabular}




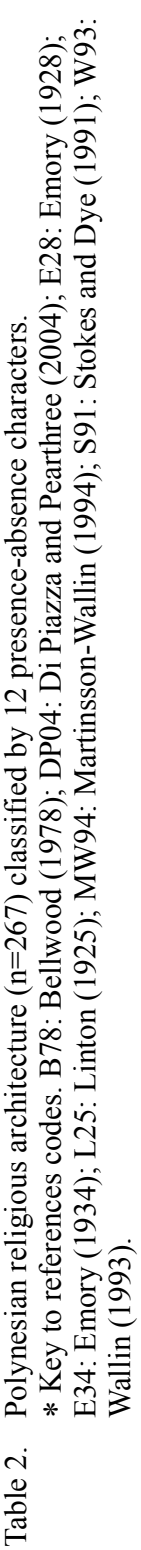

\begin{tabular}{|c|c|c|c|c|c|c|c|c|c|c|c|c|}
\hline Substructures & 0 & 0 & 0 & 0 & 0 & 0 & 0 & 0 & 0 & 0 & 0 & $\circ$ \\
\hline Dressed stone or coral & 0 & 0 & 0 & 0 & 0 & 0 & 0 & 0 & 0 & 0 & 0 & 0 \\
\hline Images & 0 & 0 & 0 & 0 & 0 & 0 & 0 & 0 & 0 & 0 & 0 & 0 \\
\hline Uprights & 一 & 一 & 一 & 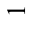 & 一 & - & 一 & 一 & 一 & 一 & 一 & 一 \\
\hline Courtyard pits & 0 & 0 & 0 & 0 & 0 & 0 & 0 & 0 & 0 & 0 & 0 & 0 \\
\hline Interior enclosures & 0 & 0 & 0 & 0 & 一 & 0 & 0 & 0 & 一 & 0 & 0 & 0 \\
\hline Interior platforms & 0 & 0 & 0 & 0 & 0 & 0 & 0 & 0 & 0 & 0 & 0 & 0 \\
\hline Interior courtyard walls & 0 & 0 & 0 & 0 & 0 & 0 & 0 & 0 & 0 & 0 & 0 & 0 \\
\hline Multiple courtyard levels & 0 & 0 & 0 & 0 & 0 & 0 & 0 & 0 & 0 & 0 & 0 & 0 \\
\hline Courtyard paving & 0 & 0 & 0 & 0 & 0 & 0 & 0 & 0 & 0 & 0 & 0 & 0 \\
\hline Courtyard walls & 0 & 0 & 0 & 0 & 0 & 0 & 0 & 0 & 0 & 0 & 0 & 0 \\
\hline Courtyard raised & 0 & 0 & 0 & 0 & 0 & 0 & 0 & 0 & 0 & 0 & 0 & 0 \\
\hline Island & 离 & 禀 & 咅 & 窇 & 竧 & 竞 & 咅 & 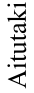 & 吾 & 离 & 禀 & 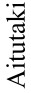 \\
\hline Site name & 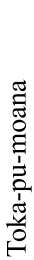 & 苂 & $\begin{array}{l}\frac{\pi}{\frac{\pi}{2}} \\
\frac{1}{2} \\
\frac{1}{\pi} \\
\frac{1}{\pi}\end{array}$ & 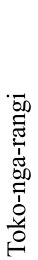 & 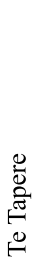 & 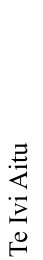 & 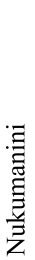 & 节 & 1 & 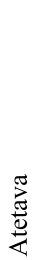 & 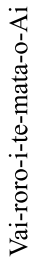 & $\begin{array}{l}\vec{Z} \\
\frac{\vec{Z}}{0} \\
\frac{1}{0} \\
0\end{array}$ \\
\hline Site designation & 点 & $\begin{array}{l}\text { 兄 } \\
\text { 学 }\end{array}$ & $\frac{\infty}{\underline{E}}$ & 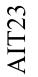 & 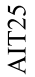 & 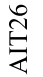 & 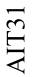 & 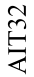 & 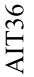 & $\stackrel{+}{\stackrel{+}{\rightleftarrows}}$ & $\stackrel{n}{\longleftarrow}$ & $\stackrel{n}{\xi}$ \\
\hline Reference * & $\frac{\infty}{\infty}$ & $\frac{\infty}{\infty}$ & $\stackrel{\infty}{\infty}$ & $\stackrel{\infty}{\infty}$ & $\stackrel{\infty}{\infty}$ & $\stackrel{\infty}{\infty}$ & $\stackrel{\infty}{\infty}$ & $\stackrel{\infty}{\stackrel{\infty}{m}}$ & $\stackrel{\infty}{\infty}$ & $\stackrel{\infty}{\infty}$ & $\stackrel{\infty}{m}$ & $\stackrel{\infty}{m}$ \\
\hline Identification no. & 一 & $N$ & $m$ & $\nabla$ & in & 6 & $r$ & $\infty$ & $a$ & 으 & 二 & 工 \\
\hline
\end{tabular}




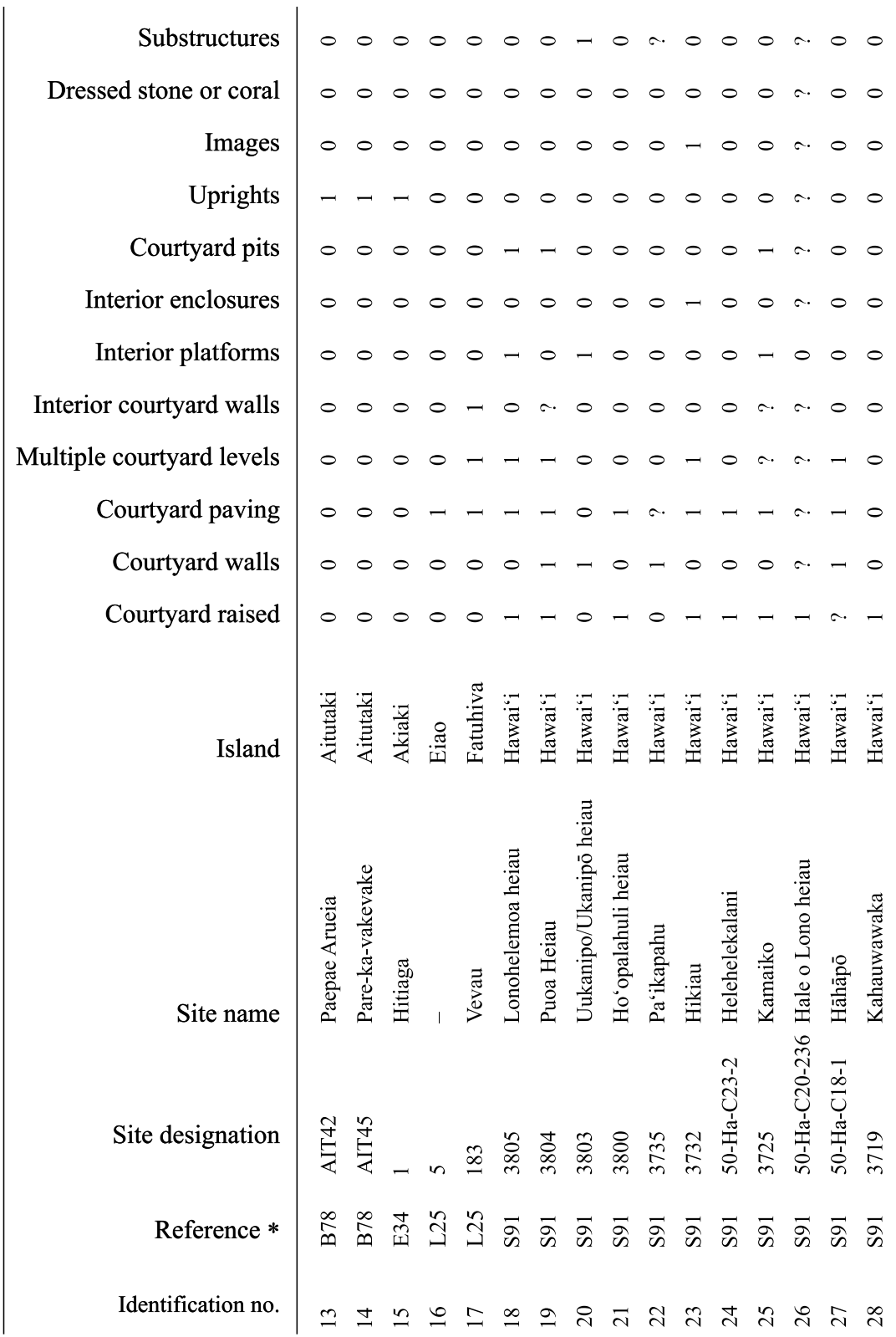




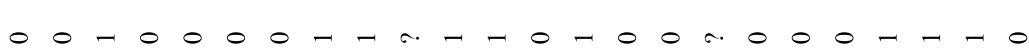

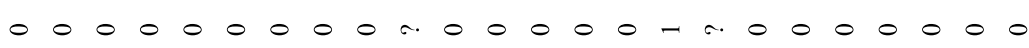

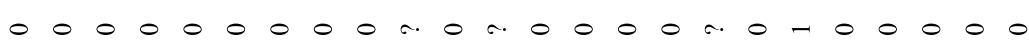

000000000 a. $00000-a .0000000$

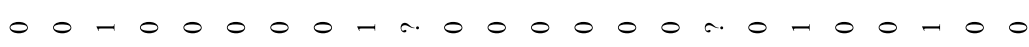

$000000000 a .000000$ a $0000-0$

$0000000-1-00-0-0000-0-1-00$

$000000-00 \pi 000000 \% 0000-00$

$000000000-\cdots-1-1-00-0-1-0-00$

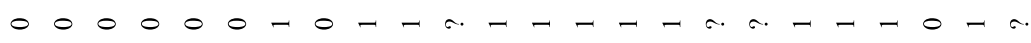

$00-1000--1-1-000-0-10-0-$

$-100-1-0-$ a

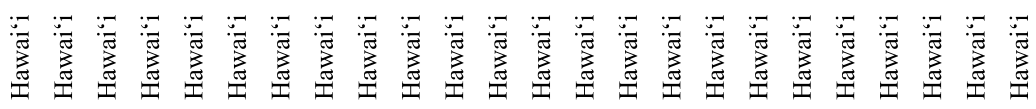

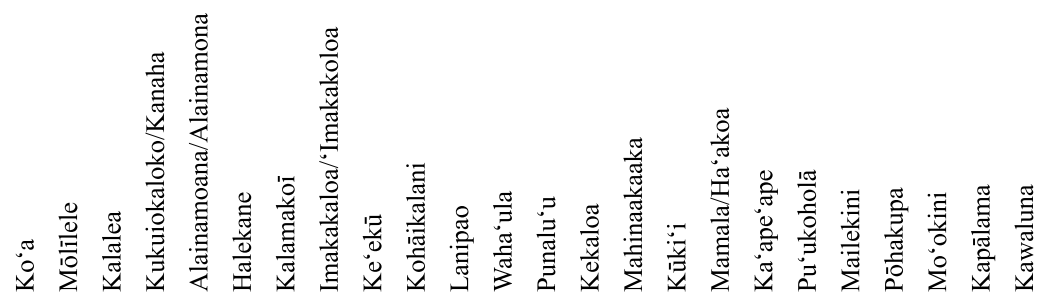

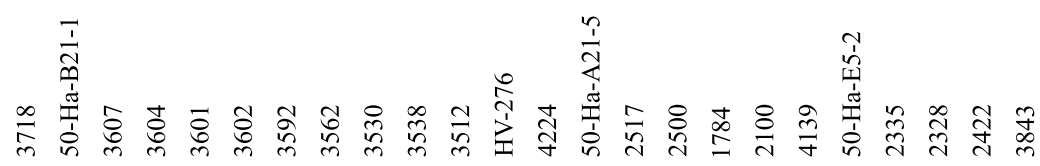

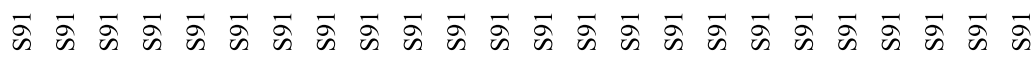

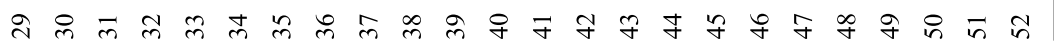




\begin{tabular}{|c|c|c|c|c|c|c|c|c|c|c|c|c|c|c|c|}
\hline Substructures & 0 & r. & 0 & - & 0 & 0 & 0 & 0 & - & 0 & - & 0 & 0 & 0 & - \\
\hline Dressed stone or coral & 0 & a. & 0 & 0 & 0 & 0 & 0 & 0 & 0 & 0 & 0 & 0 & 0 & 0 & 0 \\
\hline Images & 0 & - & 0 & - & 0 & 0 & 0 & 0 & 0 & 0 & - & - & 0 & 0 & 0 \\
\hline Uprights & $\circ$ & 0 & 0 & 0 & 0 & 0 & 0 & 0 & 0 & 0 & 0 & - & 0 & 0 & 0 \\
\hline Courtyard pits & $\circ$ & a. & - & - & 0 & 0 & 0 & 0 & 0 & 0 & 0 & 0 & - & 0 & 0 \\
\hline Interior enclosures & 0 & $\curvearrowright$. & 0 & $\sim$ & 0 & 0 & ○ & 0 & 0 & 0 & 0 & 0 & 0 & 0 & 0 \\
\hline Interior platforms & 0 & 0 & 0 & - & 0 & 0 & ○ & 0 & - & 0 & 0 & 0 & 0 & 0 & 0 \\
\hline Interior courtyard walls & ○ & 0 & 0 & - & 0 & 0 & ○ & 0 & - & 0 & - & 0 & 0 & 0 & 0 \\
\hline Multiple courtyard levels & o & $\curvearrowright$. & o & - & - & - & - & 0 & - & 0 & ○ & 0 & 0 & 0 & 0 \\
\hline Courtyard paving & - & a. & - & - & - & - & - & 一 & - & - & $\curvearrowright$. & - & 0 & 0 & a. \\
\hline Courtyard walls & - & 0 & - & - & 0 & 0 & - & 0 & - & - & 一 & 0 & - & 0 & 0 \\
\hline Courtyard raised & 0 & - & - & 0 & - & - & - & - & - & 0 & $\sim$ & - & 0 & - & - \\
\hline Island & 济 & 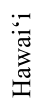 & 茜 & 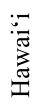 & 苟 & 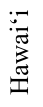 & 可 & 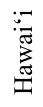 & 荡 & 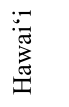 & 可 & 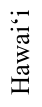 & 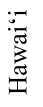 & 䓠 & 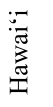 \\
\hline Site name & 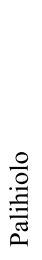 & 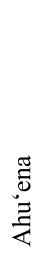 & 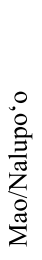 & 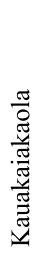 & 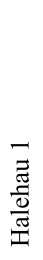 & 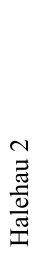 & $\begin{array}{l}\text { m } \\
\frac{\pi}{\mathbb{J}} \\
\frac{\pi}{\pi} \\
\text { I }\end{array}$ & 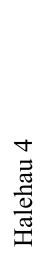 & 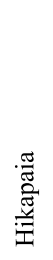 & 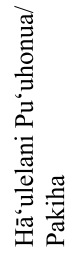 & 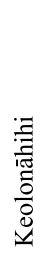 & 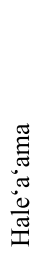 & 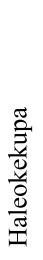 & 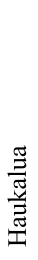 & 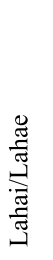 \\
\hline Site designation & 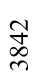 & $\underset{\infty}{\infty}$ & $\underset{\infty}{ \pm}$ & $\begin{array}{l}0 \\
\infty \\
\infty \\
m\end{array}$ & $\underset{\tilde{\infty}}{\tilde{N}}$ & $\underset{\hat{\infty}}{m}$ & $\underset{\infty}{\infty}$ & $\underset{\infty}{\infty}$ & 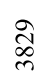 & $\vec{\infty}$ & $\underset{\substack{\infty \\
\text { N }}}{\widehat{N}}$ & $\underset{\infty}{\infty}$ & $\underset{\widetilde{\infty}}{\tilde{m}}$ & ڤे & 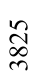 \\
\hline Reference * & $\bar{\sigma}$ & $\bar{a}$ & $\overline{\mathrm{s}}$ & $\overline{\mathrm{s}}$ & $\bar{\sigma}$ & $\overline{\text { के }}$ & $\overline{\mathscr{a}}$ & $\bar{\sigma}$ & $\overline{\text { a }}$ & $\bar{a}$ & $\bar{\sigma}$ & $\bar{\sigma}$ & $\overline{\dot{a}}$ & $\bar{a}$ & $\overline{\text { aे }}$ \\
\hline Identification $\mathrm{n}$ & $n$ & in & 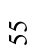 & & in & $\stackrel{\infty}{n}$ & in & 8 & 5 & $\widetilde{\sigma}$ & & to & 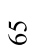 & 8 & \\
\hline
\end{tabular}


$0-00-100000000-00-10000-$

$00000000000000-1-1-1-1-1-1-0$

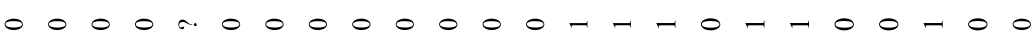

0000000000000000000000010

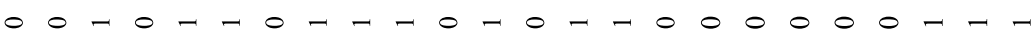

$-00000000000000000000000-$

$000-10000-0$ a 0 - 0 - - -

$-00-0-0000000-00000-0000$

$0-100000$ - 0 - 0 a 00 - 0 a h -

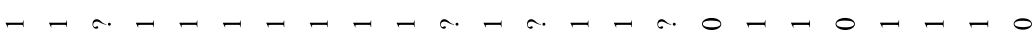

$-0-0-1-0-1-0-0-00000-0000$

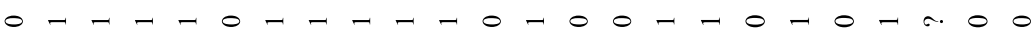

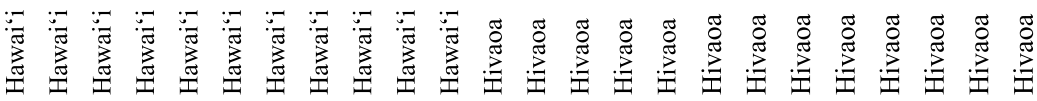

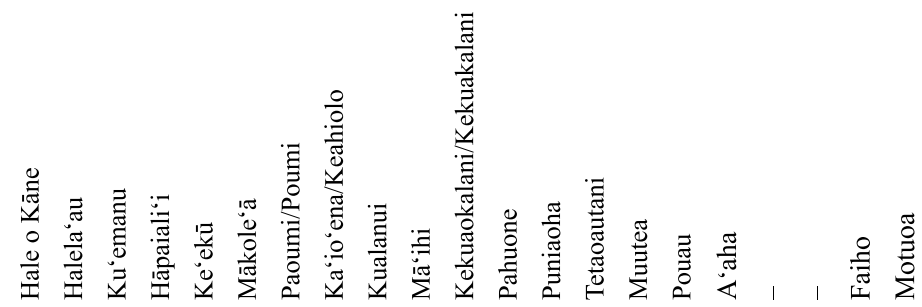

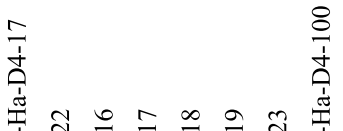

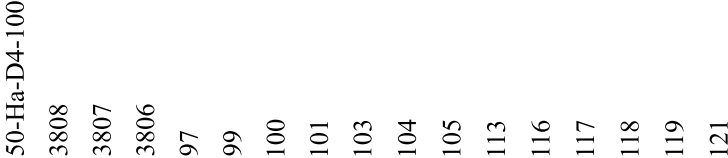

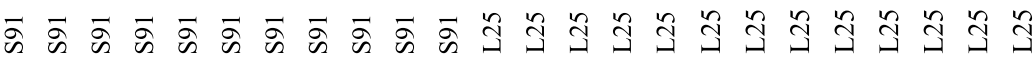

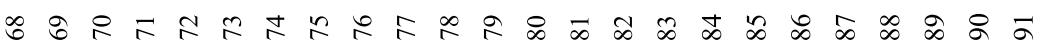




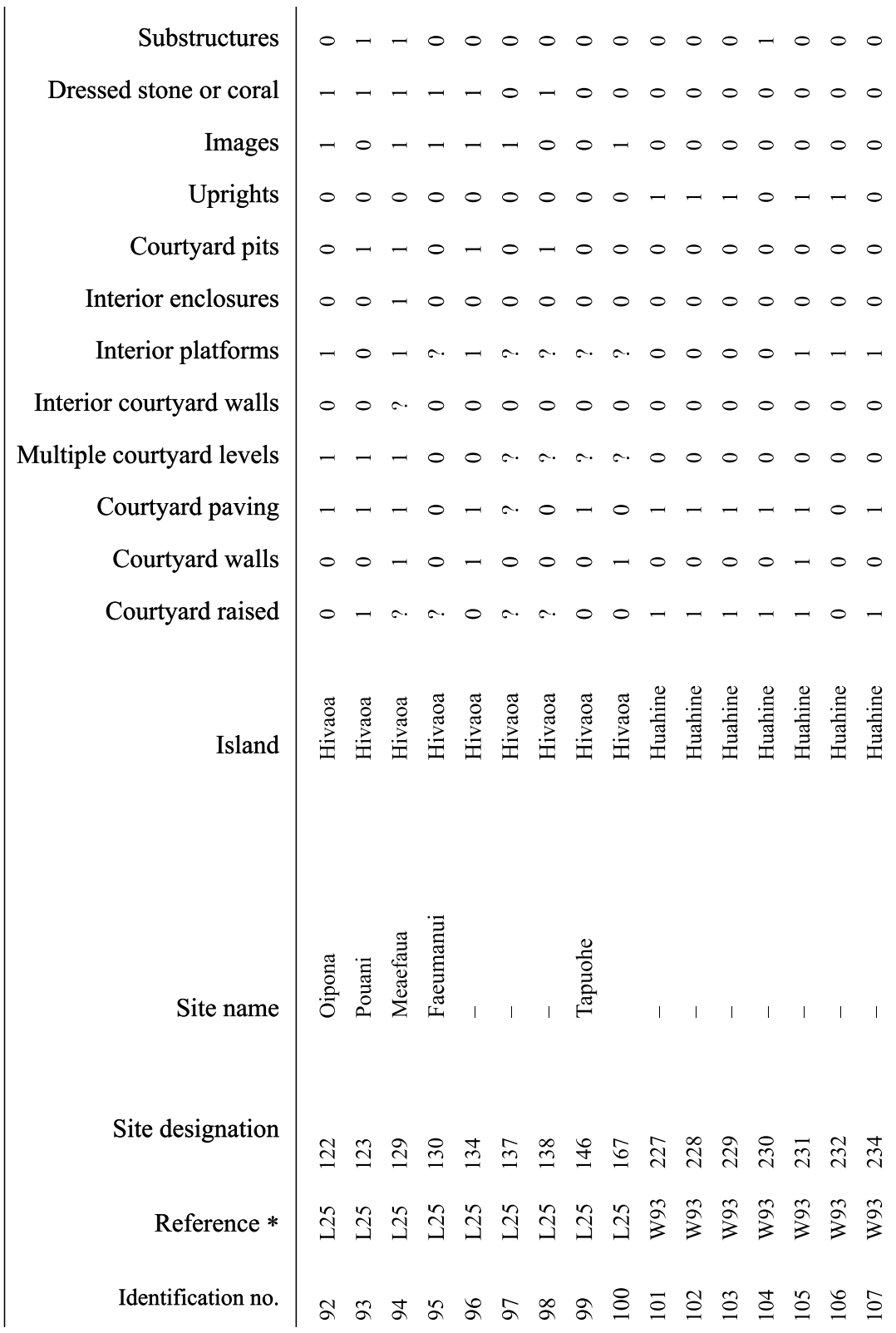




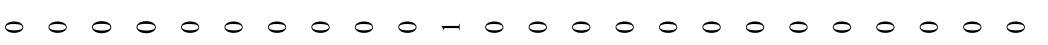

$$
\begin{aligned}
& 000000000000000000000000000 \\
& 000000000000000000000000
\end{aligned}
$$

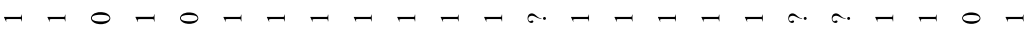

$$
\begin{aligned}
& 0000-0-000000000000000000 \\
& 00000000000000000-2.0000000000
\end{aligned}
$$

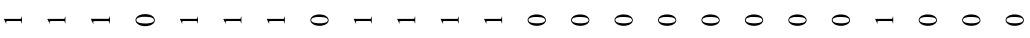

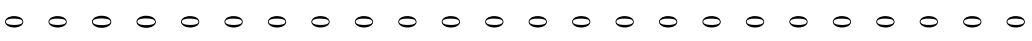

$$
\begin{aligned}
& 000000-1-00-0000000000000 \\
& -7-100-7-0-000-000000000
\end{aligned}
$$

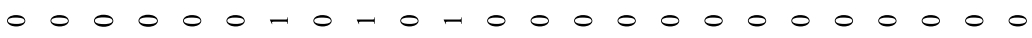

$$
\begin{aligned}
& -7-1-0000000000000000000
\end{aligned}
$$

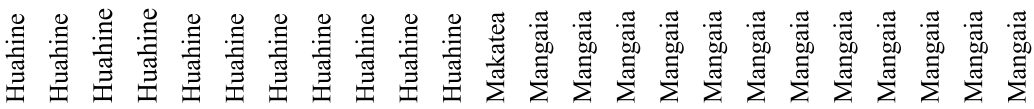

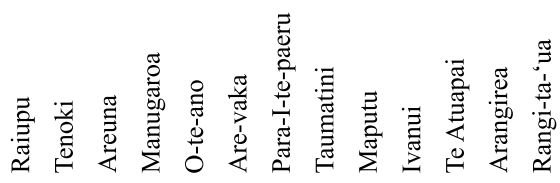

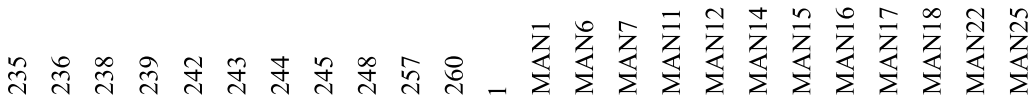

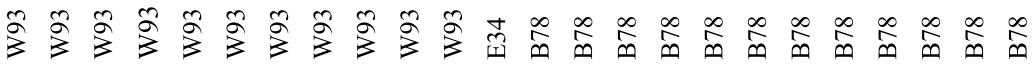

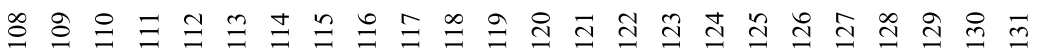




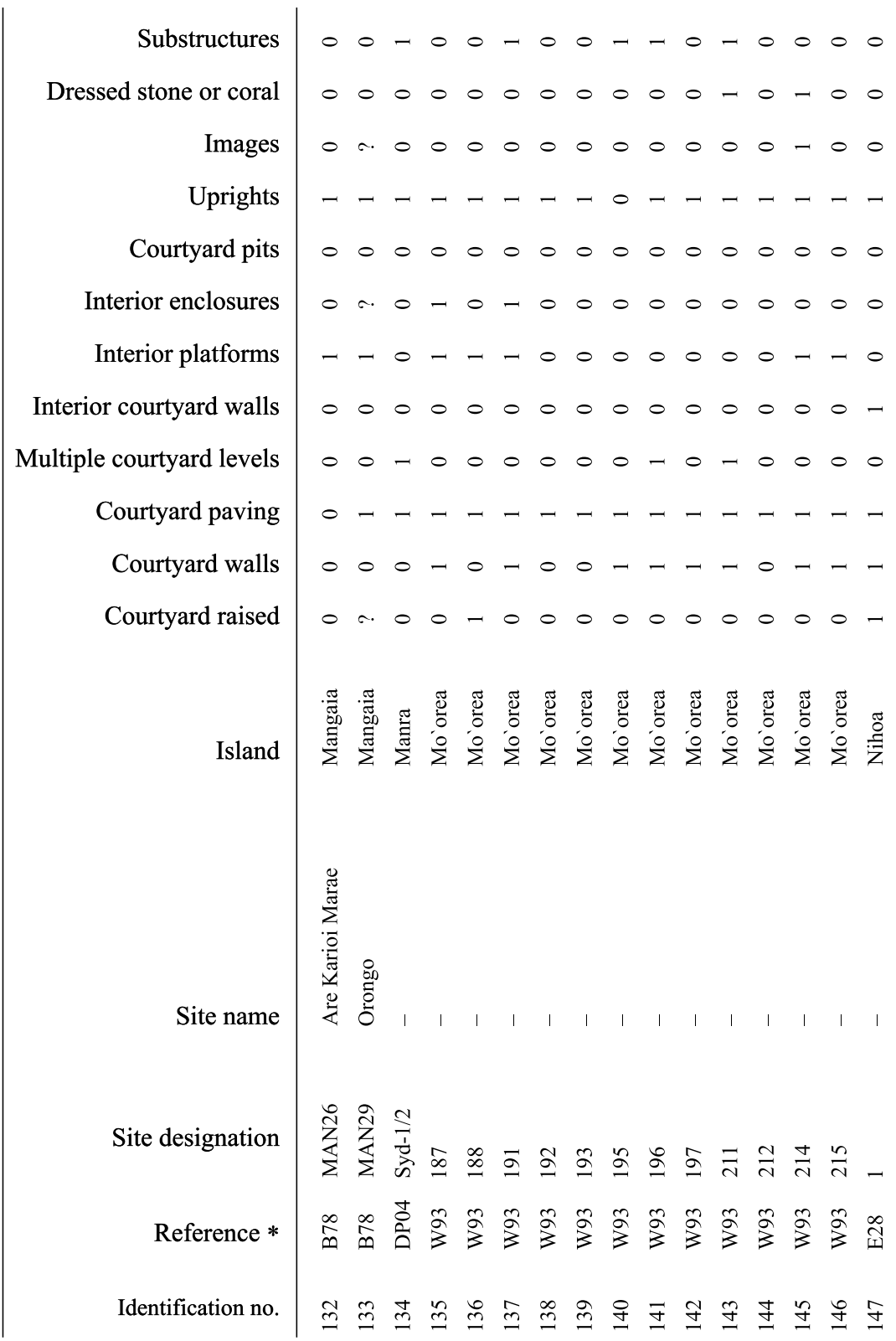




$$
\begin{aligned}
& 0-0000-0000-1-000-1-1-00000
\end{aligned}
$$

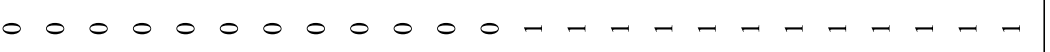

$$
\begin{aligned}
& 0000000000000000-0-0---H
\end{aligned}
$$

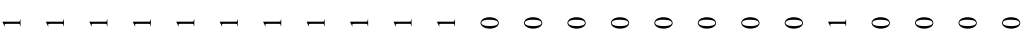

$$
\begin{aligned}
& 00000000000-0--1-0-1-00000 \\
& 0000000000000000000 \mu \cdot h \cdot h
\end{aligned}
$$

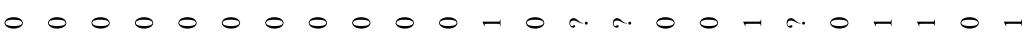

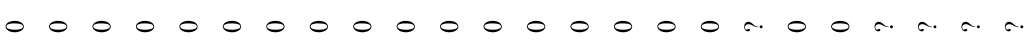

$$
\begin{aligned}
& 000000000000-\alpha+-\mu-\alpha, 00-0 \\
& \text { - H } \\
& 00000-1-0-0000000 \mu 00000- \\
& --100-0000--1-0-0 \pi-00000
\end{aligned}
$$

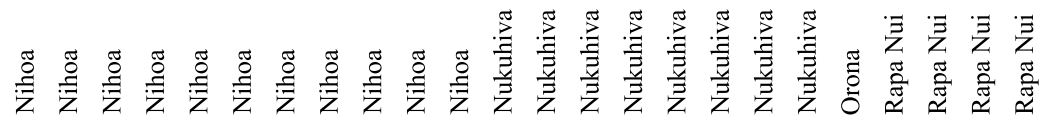

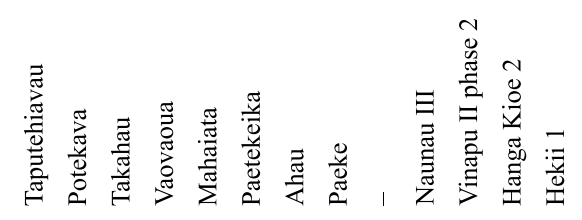

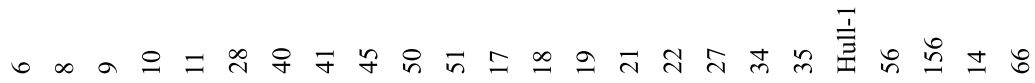

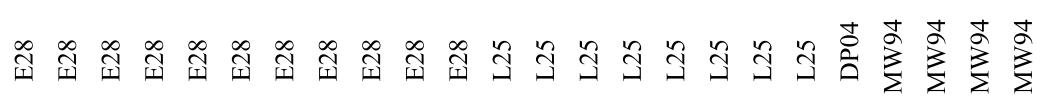

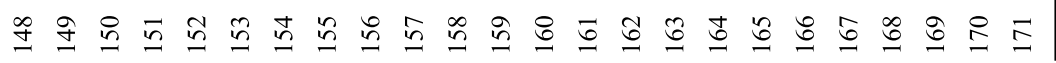




\begin{tabular}{|c|c|c|c|c|c|c|c|c|c|c|c|c|c|c|c|}
\hline Substructures & 0 & 0 & 0 & 0 & 0 & 0 & 0 & 0 & - & 0 & 0 & 0 & 0 & 0 & 0 \\
\hline Dressed stone or coral & - & - & - & - & - & - & 0 & 0 & 0 & 0 & 0 & 0 & 0 & 0 & 0 \\
\hline Images & - & - & - & - & - & - & 0 & 0 & 0 & 0 & 0 & 0 & 0 & 0 & 0 \\
\hline Uprights & 0 & o & ○ & 0 & 0 & 0 & - & - & - & - & - & - & - & - & - \\
\hline Courtyard pits & 0 & ○ & - & 0 & 0 & 0 & - & $\circ$ & $\circ$ & 0 & ○ & 0 & 0 & 0 & 0 \\
\hline Interior enclosures & $\curvearrowright$ & $\sim$ & $\curvearrowright$ & $\curvearrowright$ & $\sim$ & $\curvearrowright$ & - & $\circ$ & $\sim$ & 0 & 0 & 0 & $\circ$ & $\curvearrowright$ & $\circ$ \\
\hline Interior platforms & - & - & - & - & - & - & ○ & 0 & - & $\circ$ & 0 & - & $\circ$ & 0 & $\circ$ \\
\hline Interior courtyard walls & a. & - & $\curvearrowright$. & 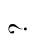 & a. & $\curvearrowright$ & $\circ$ & $\circ$ & ○ & ○ & ○ & 0 & 0 & 0 & 0 \\
\hline Multiple courtyard levels & ○ & ○ & 0 & 0 & ○ & o & 0 & 0 & o & ○ & ○ & 0 & 0 & $\circ$ & ○ \\
\hline Courtyard paving & $\circ$ & a. & - & - & a. & - & - & - & - & - & - & - & - & - & $\circ$ \\
\hline Courtyard walls & - & o & - & o & a. & ○ & $\circ$ & $\circ$ & $\circ$ & ○ & ○ & 0 & o & ○ & ○ \\
\hline Courtyard raised & 0 & 0 & 0 & 0 & 0 & 0 & o & 0 & 0 & 0 & ○ & o & 0 & 0 & o \\
\hline Site name & 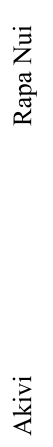 & 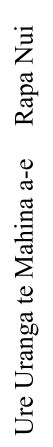 & 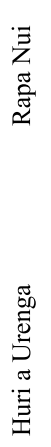 & $\begin{array}{l}\vec{z} \\
\frac{\vec{a}}{a} \\
\frac{0}{0} \\
\dot{a}\end{array}$ & 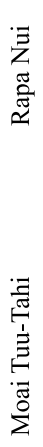 & 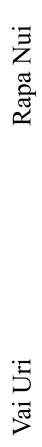 & 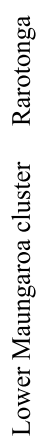 & 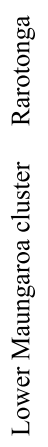 & 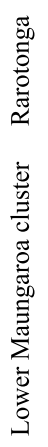 & 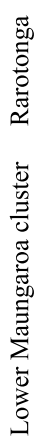 & 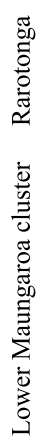 & 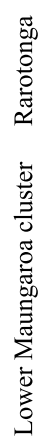 & 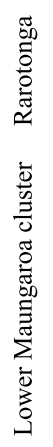 & 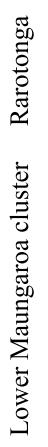 & 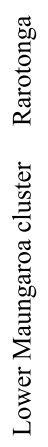 \\
\hline Site designation & $\stackrel{i}{ }$ & $\stackrel{ \pm}{\beth}$ & 吉 & $=$ & ๖ & $\infty$ & $\underset{n}{\bar{n}}$ & $\stackrel{m}{n}$ & $\stackrel{n}{i n}$ & $\frac{a}{n}$ & $\equiv$ & $\stackrel{n}{\lessgtr}$ & $\stackrel{\stackrel{\rho}{\lessgtr}}{i}$ & $\underset{i}{\stackrel{n}{n}}$ & $\underset{n}{\stackrel{J}{n}}$ \\
\hline Reference $*$ & $\sum_{\Sigma}^{J}$ & $\sum_{\Sigma}^{J}$ & $\sum_{\Sigma}^{J}$ & $\sum_{\Sigma}^{+}$ & $\stackrel{\Xi}{\Sigma}$ & $\stackrel{\Delta}{\Sigma}$ & $\stackrel{\infty}{\infty}$ & $\stackrel{\infty}{\infty}$ & $\stackrel{\infty}{\infty}$ & $\stackrel{\infty}{\stackrel{\infty}{n}}$ & $\stackrel{\infty}{\infty}$ & $\stackrel{\infty}{\stackrel{\infty}{n}}$ & $\stackrel{\infty}{\infty}$ & $\stackrel{\infty}{\infty}$ & $\stackrel{\infty}{\infty}$ \\
\hline Identification $n$ & $\sqrt{2}$ & 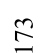 & 过 & 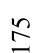 & 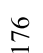 & 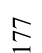 & $\stackrel{\infty}{\sim}$ & 2 & $\infty$ & $\bar{\infty}$ & $\stackrel{\infty}{\infty}$ & $\infty$ & $\forall$ & $\infty$ & 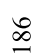 \\
\hline
\end{tabular}




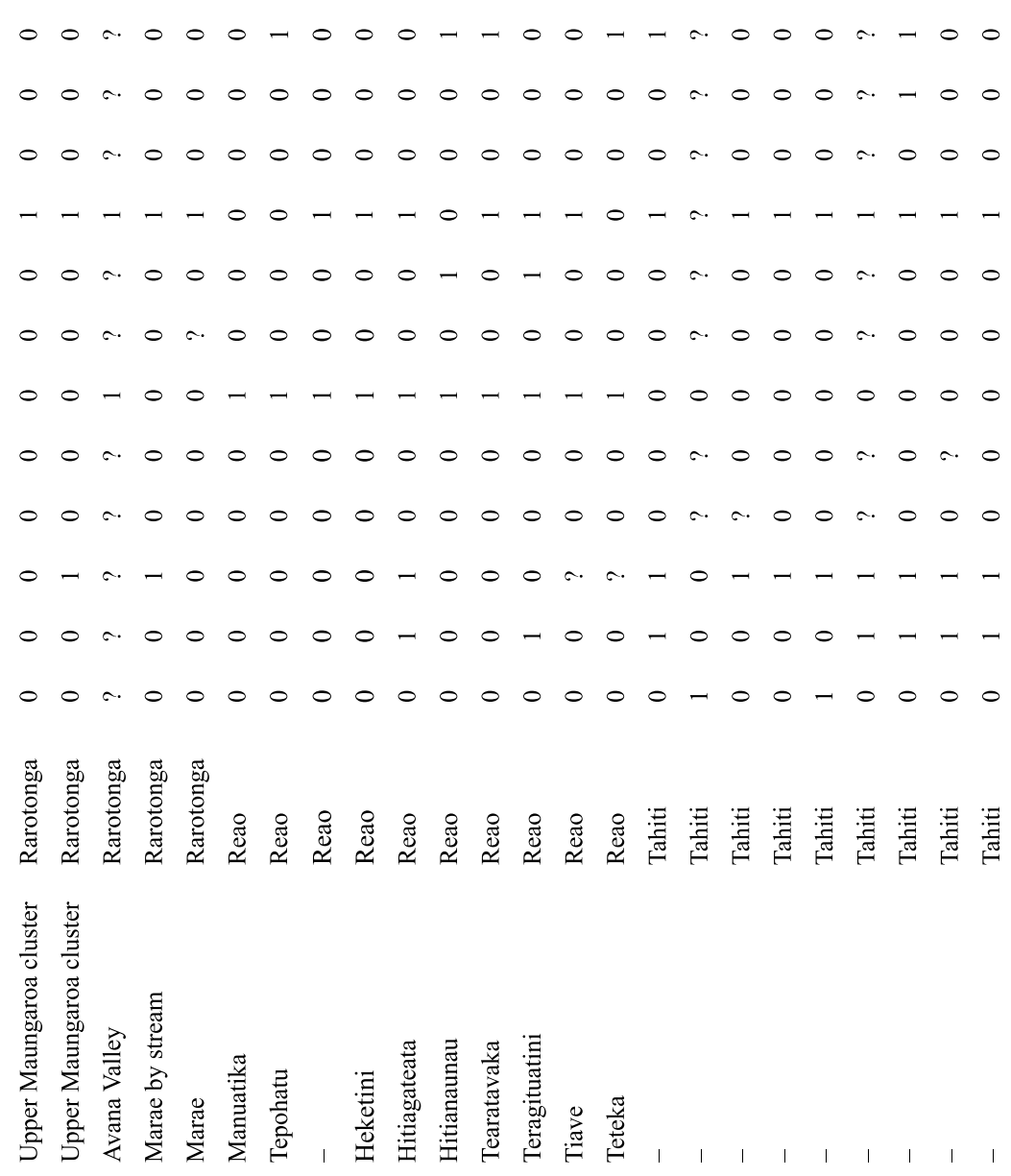

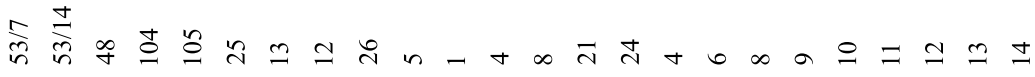

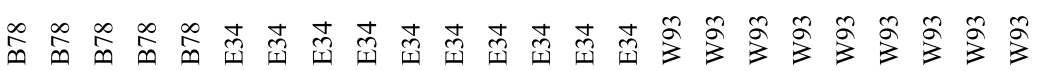

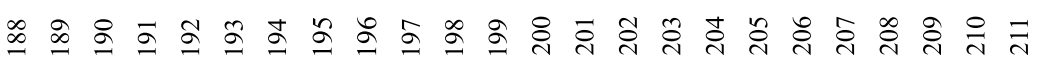




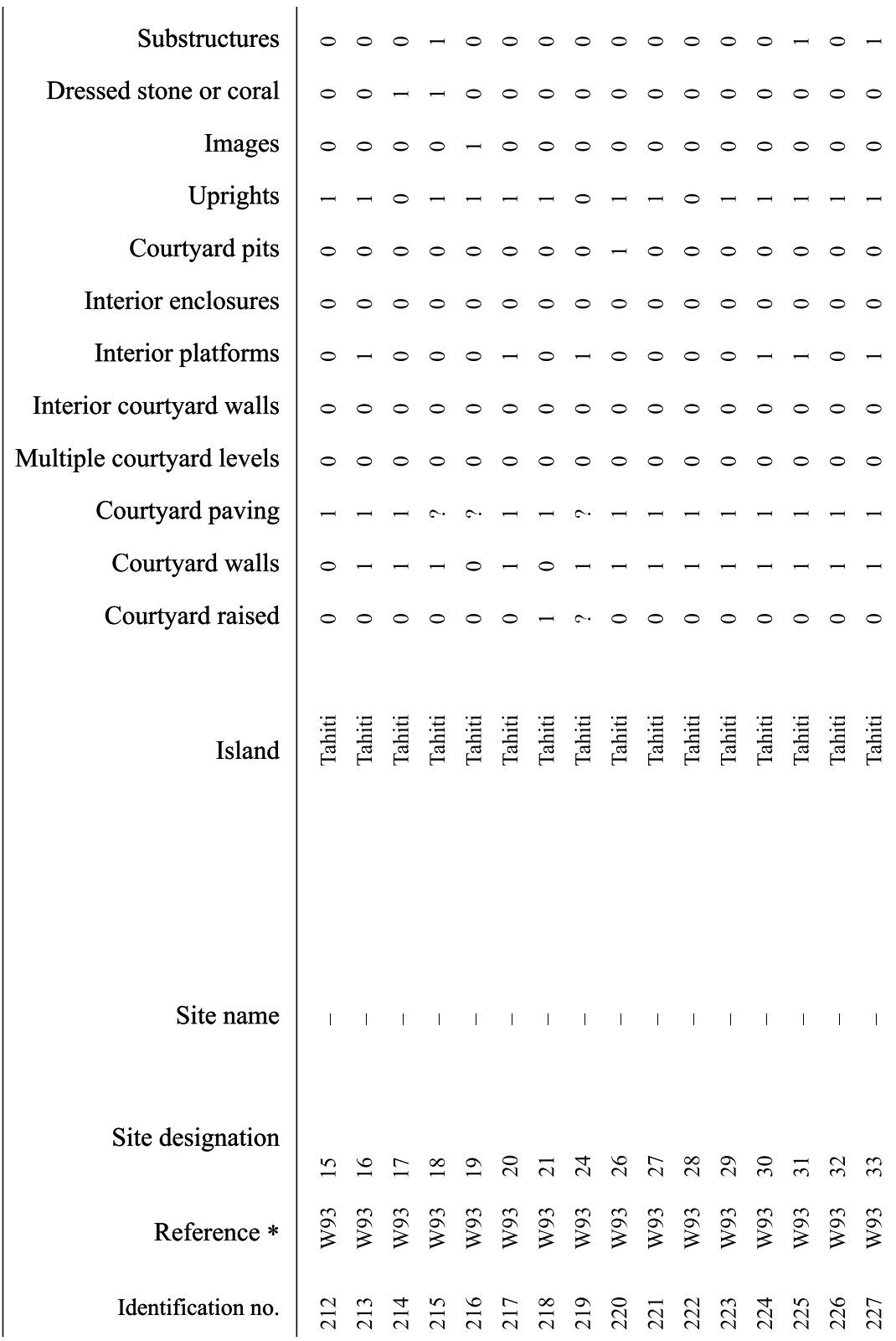




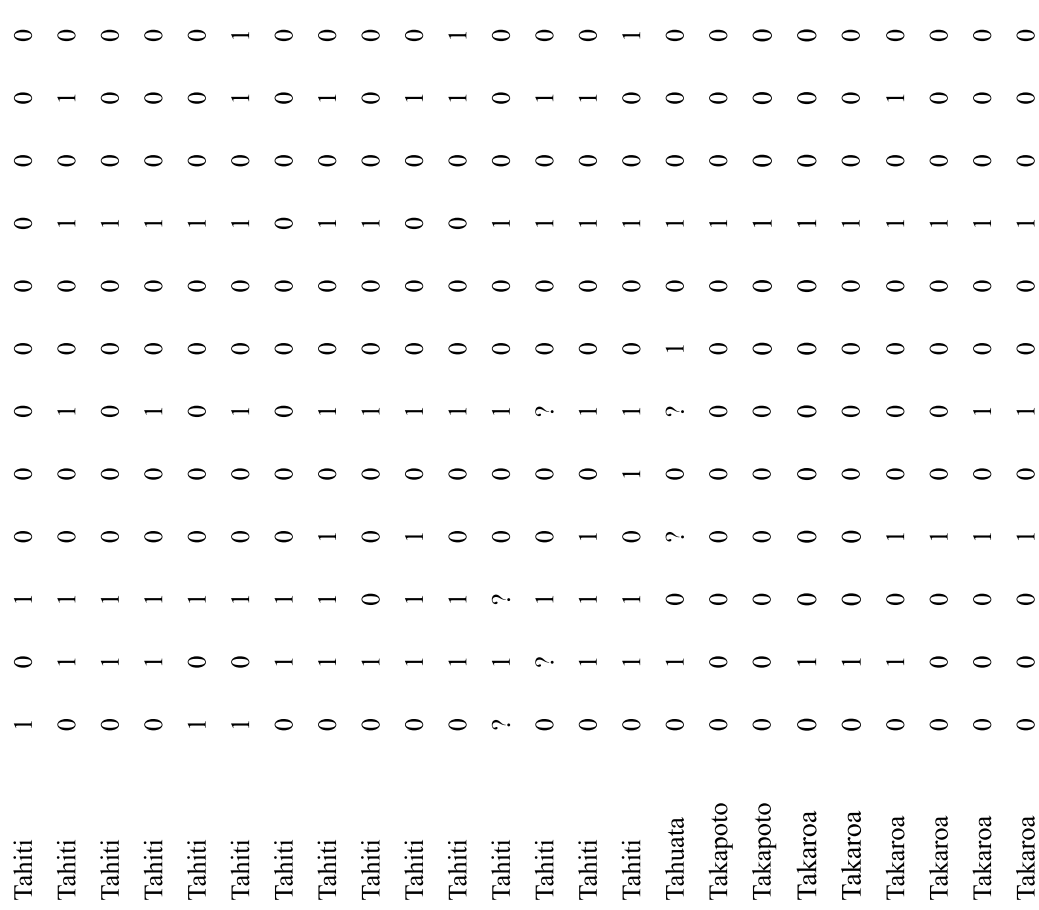




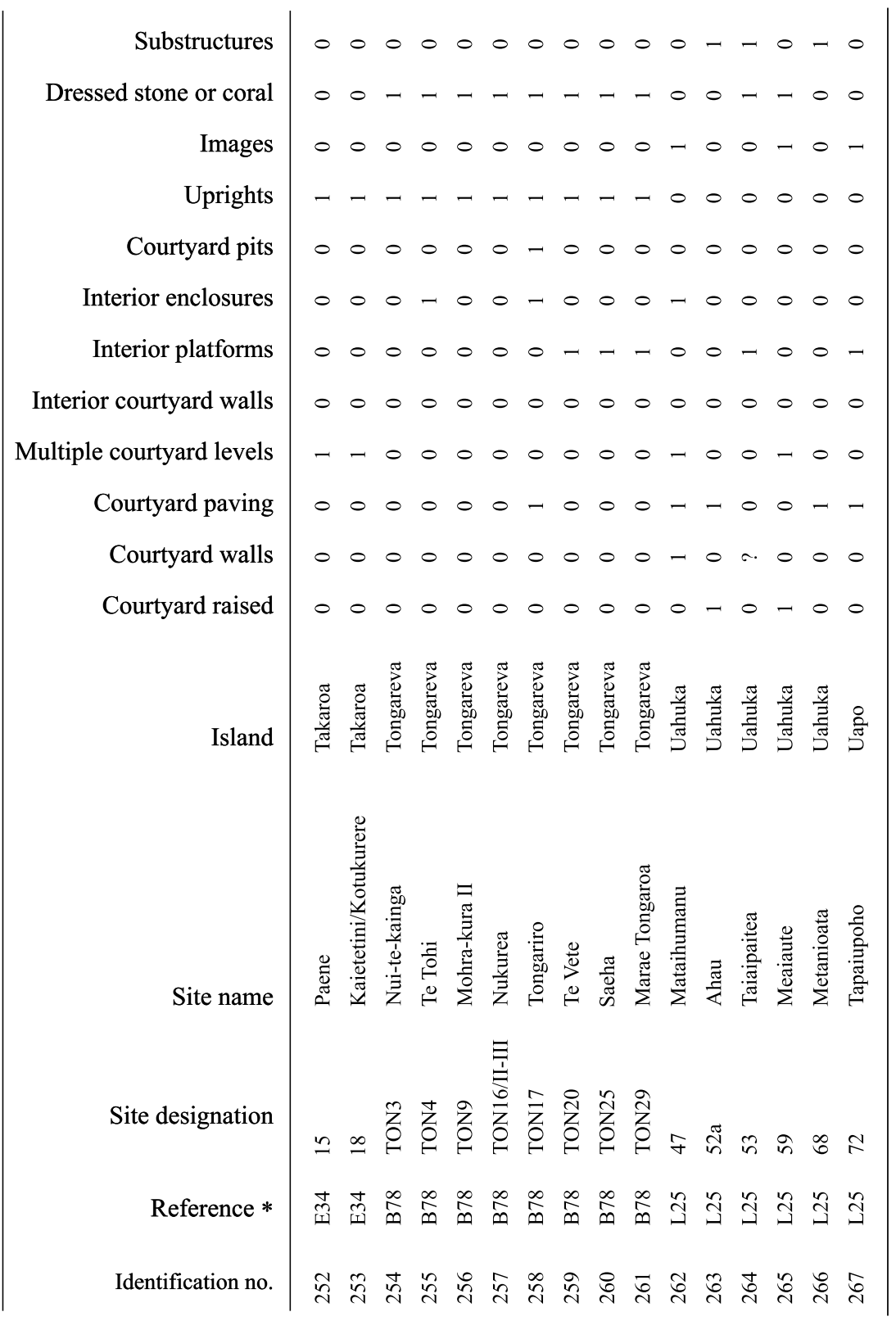




\section{CLASSIFICATION AND CLADISTIC ANALYSES}

Using the 198 structures with known observations in all 12 characters (i.e., no question marks in Table 2) there are 104 taxa or classes defined by unique combinations of character states and these taxa are distributed across East Polynesia. Computationally, this is too many taxa for efficient cladistic analysis and 80 ( 77 percent) of these taxa have only one member, suggesting the 12-character taxa definitions do not adequately generate variation that can be analysed with cladistics to examine cultural transmission. Put another way, the 12-character taxa are too exclusive and not repeated at a high enough frequency over time and across space. Therefore, taking a trial and error approach to classification, different numbers and combinations of characters were used to create new classifications, noting with each classification the taxa with empirical members amongst the ritual architecture and the number of structures in each taxon. The resulting classification using six characters generates variation, that when analysed with cladistics, appears to be explicable by cultural transmission. Specifically, there are a reasonable number of taxa (25), these appear across different Polynesian islands and the number of structures in each taxon varies between 1 and 34 (median $=4)$. The six character classification includes the following characters, in order: (i) courtyard raised, (ii) courtyard partially/completely walled, (iii) courtyard partially/completely paved, (iv) interior platforms, (v) uprights and (vi) images. A taxon definition can be efficiently represented as a string of $0 \mathrm{~s}$ and $1 \mathrm{~s}$, so for example a raised and paved courtyard with an interior platform is defined with the number string 110100 .

Without attempting to minimise tree-length, there are over $5.8 \times 10^{49}$ different branching trees that could be constructed with 25 taxa. Computer software allows us to search this "tree space" for the most parsimonious trees and a sample of one million equally parsimonious trees of length 25 were generated by the cladistic analysis using PAUP*4.0 software (Swofford 2001) and the "branch and bound" heuristic search option. These trees are the most parsimonious arrangements that could be generated given the limits of computer power. A consensus tree depicting the bifurcating relationships present in 50 percent or more of the one million equal length trees is shown in Figure 4. This tree is one hypothesis of the phylogenetic relationships between ritual architecture taxa and suggests that, except for some architecture in the Marquesas and Society Islands, there are no clear phylogenetic relationships for specific sets of taxa. Two architectural taxa found in the Marquesas and Society Islands (101100 and 101101) are defined by raised, paved courtyards, without walls and comprising multiple levels. These taxa are possibly more closely related to each other than to other taxa in the analysis. One of the architectural classes, found only on Hiva Oa (Marquesas Islands), also has 
Taxon 101101

Hiva Oa

Taxon 101100

Nuku Hiva

Hiva Oa

Huahine

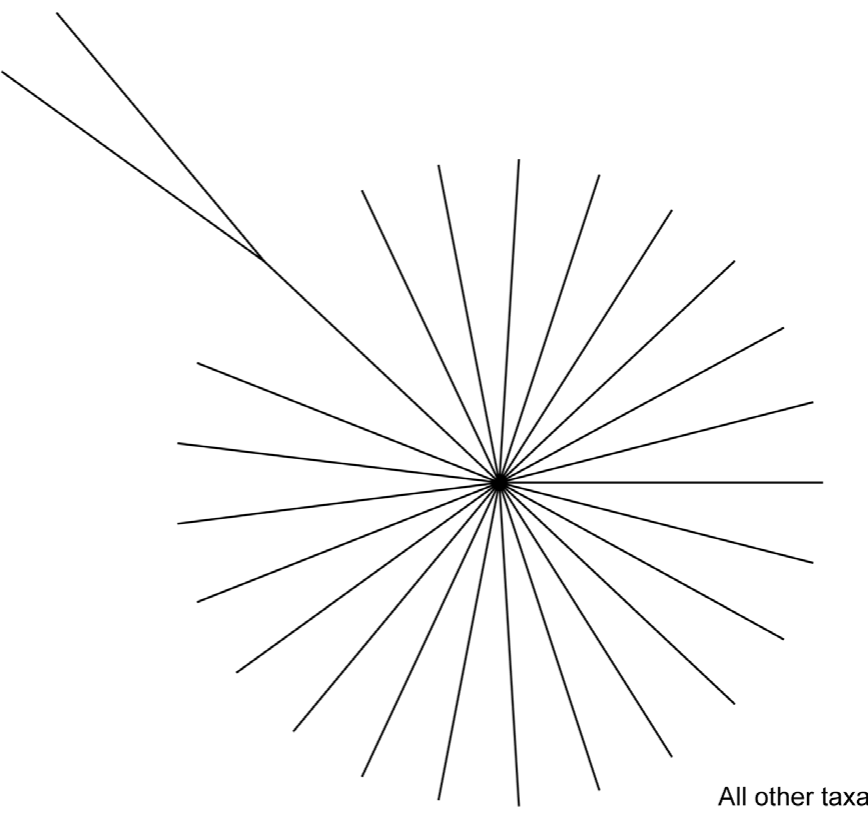

Figure 4. Unrooted cladistic tree showing relationships between 25 ritual architecture taxa. The number string indicates the presence-absence of the six characters defining the taxa (characters are in same order as described in text) and the island name indicates where the taxon is found. The tree has a CI of 0.24 and an RI of 0.61 (see text for definitions).

stone images. The remaining taxa in the group of unresolved relationships are distributed across all islands in Figure 3 except Nihoa, which did not have any architectural features included in the six character classification used here. Finally, Figure 4 is called an unrooted tree as no outgroup has been selected as a kind of "starting point" to trace the relationships in the tree. However, choosing any of the taxa in the tree as an outgroup, including the taxon with an absence in all characters (000000), does not change the structure of the relationships depicted in Figure 4, except that the taxon chosen as the outgroup is removed.

In addition to length, this tree also can be characterised by two additional statistical summaries that give some indication of the ability to arrange 
the taxa in a clearly branching set of relationships. The Consistency Index (CI) is a measure of the amount of homoplasy in a tree, calculated by dividing the number of character states of the analysed taxa ( 12 here) by the number of character states displayed on the tree. The CI can range between zero (complete homoplasy) and one (no homoplasy). Greater amounts of homoplasy (i.e., CI values approaching zero) confound efforts to generate cladistic trees composed of bifurcating branches. The CI of the tree in Figure 4 is 0.24 . The other summary measure is the Retention Index (RI) and is calculated by noting the amount of similarities in different lineages on a tree that do not represent taxa relatedness (i.e., observed homoplasy), and comparing this with the maximum possible amount of these similarities given the taxa definitions (i.e., maximum homoplasy). The RI measures the actual amount of homoplasy relative to the maximum amount of homoplasy and ranges from zero to one. Higher RI values occur when character state changes are concentrated primarily at the branching points of a tree and lower RI values occur when character state changes are concentrated at the tips of branches. Thus the higher the RI the more confidence we have that the tree is an accurate representation of phylogenetic relationships among taxa (Siebert 1992). The RI of the tree in Figure 4 is 0.61 and is similar to the RI of cladistic trees constructed from biological taxa and many cultural data sets (see Collard et al. 2006).

Seven of the taxa in the Figure 4 tree describe only a single piece of architecture. If we are interested in examining similarities produced through culturally transmitted and repeated behaviours, removing such unique or idiosyncratic examples may produce phylogenetic patterns that better characterise the majority of the effective population (see O'Brien et al. 2001: 1128). To explore this, a second cladistic analysis was run using the subset of 18 taxa that had multiple members. The phylogenetic relationships amongst these taxa are shown in the consensus tree in Figure 5. This is a 50 percent majority rule consensus tree built from the total sample of 378,796 possible trees of length 17, the shortest, or most parsimonious, tree length recovered by the PAUP* 4.0 software. This tree contains more resolved relationships than the Figure 4 tree, but for two-thirds of the taxa ("all other taxa" in the figure) it is still not possible to specify particular patterns of phylogenetic similarity. As with the tree in Figure 4, no outgroup has been specified for the Figure 5 tree. If a particular taxon is chosen as the outgroup, the cultural ancestor-descendent relationships in the tree are reckoned from that "starting point". For example, by choosing taxon 001101 that appears only on Rapa Nui as our outgroup, all remaining structures share a common ancestor in taxon 011101, which appears only in Rapa Nui and Hiva Oa Island in the Marquesas (cf. Martinsson-Wallin et al. 2013). 


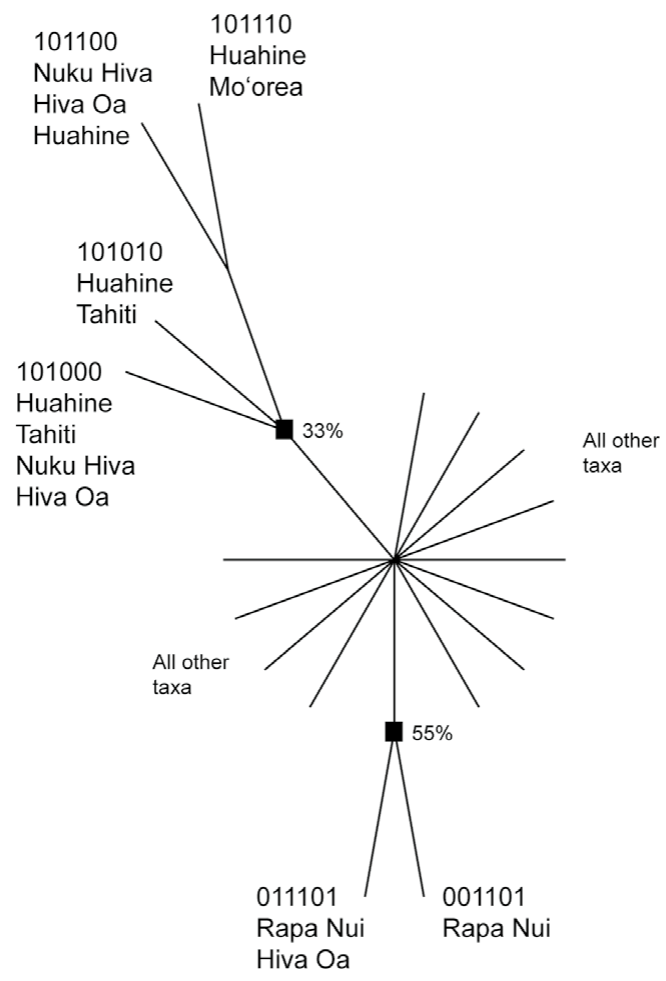

Figure 5. Unrooted cladistic tree showing relationships between 18 ritual architecture taxa with two or more members. The number string indicates the presence-absence of the six characters defining the taxa (characters are in same order as described in text) and the island name indicates where the taxon is found. The tree has a CI of 0.35 and an RI of 0.65 . Bootstrap percentages of two branches are noted.

In this tree a series of taxa defined by raised and paved courtyards without walls (101 as first character states in taxa definitions) from the Marquesas and Society Islands have partially resolved relationships. The 101100 and 101110 taxa are more closely related to each other than either is to the remaining taxa on this branch. On another partially resolved branch, taxa from Rapa Nui and Hiva Oa in the Marquesas are more closely related to each other than either is to the remaining taxa. Unsurprisingly, the CI and RI measures for this tree are a bit higher than the Figure 4 tree, 0.35 and 0.65 , respectively. 
Bootstrap values are another measure of confidence that a tree is valid representation of taxa relationships. Bootstrap values are computed by first creating a number of pseudo-data matrices through randomly resampling the original data matrix (here, the taxon definition number strings) with replacement. This creates a sample of pseudo-data matrices that randomly decreases the importance of some characters and increases the importance of others in generating bifurcating splits. Cladistic analyses are run on the pseudo-matrices and the results compared to the cladistic tree produced from the original data. The frequency with which tree branches from the original analysis appear in the pseudo-data matrix analyses are considered the bootstrap values and can be treated as a measure of confidence in that particular tree branch. If a particular tree branch from the original data appears at a high frequency in the pseudo-data matrix analyses, then we can be confident that even with random data "massaging", the original branches are robust. For this analysis, 25 pseudo-matrices were generated from the original data matrix and each of them subjected to cladistic analysis (using default settings in PAUP*4.0) wherein a maximum of 500,000 equally parsimonious trees were retained. The Rapa Nui-Hiva Oa branch has a bootstrap value of 55 percent and typically researchers only consider values above 50 to indicate a robust relationship between taxa, although this is debated (Kitching et al. 1998). The other branches in the tree do not have similar bootstrap support. Bootstrap analysis could not be performed on the 25 taxa tree (see Fig. 4) due to limited computing power.

$$
\text { *** }
$$

Clear phylogenetic patterns among ritual architecture taxa, and the branching cladistic trees that may represent them (e.g., Fig. 2), would be produced if sets of character states were differentially distributed through time and across space, with some character states appearing in more than one set and thus usefully conceptualised in ancestor-descendant relationships. However, cladistic analysis of 198 pieces of Polynesian ritual architecture-heiau, marae, ahu-moai (Rapa Nui statues and platforms) and the like- shows almost no clear phylogenetic patterns or specific lineages of cultural transmission, save for the greater phylogenetic similarity shared by some architectural taxa from Rapa Nui and the Marquesas Islands that display anthropomorphic images. Such a lack of clear phylogenetic pattern might be the result of at least three processes: (i) high cultural trait innovation rates (Nunn et al. 2010) resulting in many observed character states, (ii) very high levels of horizontal trait transmission (Greenhill et al. 2009) or a great amount of cultural sharing between populations and (iii) taxa definitions that do not generate variation associated with phylogenetic relationships when analysed with cladistics. 
While not an explanatory process per se, it is possible that the ritual architecture classification does not adequately generate variation that can be readily depicted in a cladistic tree of bifurcating branches. The classes or taxa do appear to exhibit the necessary qualities for an analysis of phylogenetic similarity (see above), but their usefulness might be limited by the presenceabsence nature of the character states. Multi-state characters, those with more than two states, would likely produce classes that encompass more variation, but such classes might have fewer members as a consequence and therefore be more limited in their spatial and temporal distributions.

Classification issues aside, a great amount of cultural sharing across East Polynesia would have been facilitated by the rapid initial colonisation of the region (see Wilmshurst et al. 2011) and continued interaction between archipelagos for some time after colonisation as evidenced by the distribution of non-local artefacts (Allen 1996, McAlister et al. 2013, Rolett 2002, Weisler and Kirch 1996). A high level of cultural sharing or horizontal trait transmission is also suggested by other research. Rogers and colleagues (2009) examined the phylogenetic relationships of ethnographically described canoes across Polynesia using cladistics and other techniques. They created three cladistic trees, one based on stylistic characters, one based on functional characters and a third tree that combined the two. The CI and RI for these trees ranged from 0.42 to 0.66 and 0.33 to 0.5 respectively, similar to the CIs and RIs obtained here (they did not conduct cladistic bootstrap analyses). Rogers and colleagues (2009: 3840) conclude that their "cultural data do not simply reflect a pattern of vertical (i.e., intra-group) trait transmission with sequential bifurcation over time", but that processes such as cultural transmission between different island populations may explain the data. Similarly, Larsen (2011; see also Tolstoy 2008) conducted cladistic analyses of Polynesian barkcloth manufacturing and the trees she generated also do not have very strong support for some of the branching patterns they contain. Her dataset includes barkcloth techniques from the Cook, Society, Austral, Marquesas, and Hawaiian Islands along with Mangareva, Rapa Nui, and a set of West Polynesian islands. In the two trees she generates there are only two East Polynesian branches with greater than 50 percent bootstrap support. The branch or clade containing the Cooks, Society and Austral Islands is supported by a 64 percent bootstrap value and within this the Cooks-Society branch has a 75 percent bootstrap value. Combined with the CI and RI of these trees, 0.48 and 0.54 respectively, her results also suggest cultural sharing or horizontal trait transmission within, but not between, the West Polynesian and East Polynesian regions. Considering quantitative phylogenetic analyses of East Polynesian material culture, there are only these few studies of canoes, barkcloth and the architecture to date, but each has suggested that there was 
frequent cultural sharing across islands and archipelagos, at least frequent enough that standard cladistic analysis does not produce statistically robust branches or clades. Other researchers examining different data sets and using a variety of techniques have also identified relatively high levels of interaction between East Polynesian populations, followed by a substantial decline in interaction. Possible explanations for changes in interaction frequency include local socio-political conflict (Rolett 1998), climate change (Bridgman 1983) and resource depression (Weisler 2004). We might expect the most powerful explanations will be those that employ processes relevant to multiple, different data sets and are linked to empirical observations. Processes from population ecology and cultural transmission models (e.g., Shennan et al. in press, Steele 2009) are promising starting points.

In addition to high levels of cultural transmission, the cladistic analyses might also indicate that Polynesian ritual architecture was a realm of material culture with high levels of trait innovation. Nunn et al. (2010) have demonstrated through simulations that increases in the rate of trait innovation can increase homoplasy (independent invention, see above) in a dataset, possibly resulting in cladistic trees with many unresolved relationships (i.e., Figs 4 and 5). High levels of innovation in ritual architecture are suggested by the early construction of the rather unique ahu-moai (Fig. 6) possibly very soon after the colonisation of Rapa Nui (Hunt 2007), and the rapid

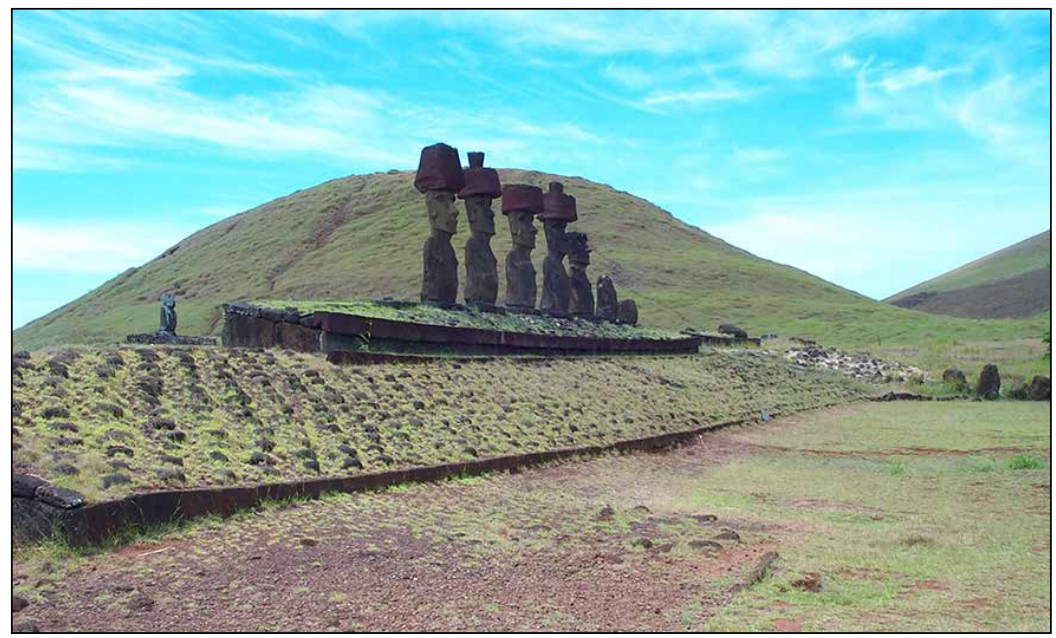

Figure 6. Ahu Naunau, Rapa Nui. Photo by Thegn Ladefoged. 
change of marae forms in the Society Islands, although this pertains mostly to architecture built several hundred years after colonisation (Kahn 2010, Sharp et al. 2010). To better assess the possibility of high innovation in ritual architecture, additional classifications using multi-state characters (i.e., not presence-absence) should be created and the character-state distributions examined. What processes might explain high levels of trait innovation in ritual architecture? From the perspective employed here, innovation is a function of population size and the connectedness between populations and environmental and cultural diversity and thus we might begin with concepts that integrate these dimensions of human life (e.g., Fitzhugh 2001, Kandler and Laland 2009, Ormerod 2005).

The only moderately clear phylogenetic relationships occur among two taxa (ahu-moai and me 'ae with images) from Rapa Nui and Hiva Oa in the Marquesas (see Fig. 5). The relationships among the taxa in the Rapa Nui-Hiva Oa clade are unresolved given that no one outgroup seem better than another, although Martinsson-Wallin et al.'s (2013) proposal that ritual architecture is first constructed in Rapa Nui might suggest ahu-moai taxon 001101 as the best outgroup. Minimally, the cladistic tree here confirms a phylogenetic relationship between some of the Marquesan and Rapa Nui ritual architecture.

Also in the Figure 5 tree is a group of related taxa from the Marquesas and the Society Islands, although this clade does not have strong bootstrap support. The taxa all share raised, paved courtyards without walls, and vary in the presence of interior platforms and uprights. None have anthropomorphic images. Interestingly all the taxa in this clade contain architecture from near Mata'ire'a Hill, Huahine Island and suggest that the clade may result from cultural transmission within the Huahine population and between Huahine and other islands. This clade could be related to new religious practices in the Society Islands, as both Kahn (2010) and Wallin and Solsvik (2010) have noted that the spread of the 'Oro cult from the Leeward Islands (including Huahine) to the Windward Islands (including Mo'orea, also present in this clade) was associated with a new marae architecture that would likely fit within some of the taxa definitions in this clade.

These hypotheses concerning innovation and interaction in the realm of ritual architecture and the origins and spread of architectural taxa must be considered in light of classification issues and the assemblage of ritual architecture analysed here. Other taxa definitions using different characters and character states will produce different cladistic trees. However, the taxa arranged in the cladistic trees in Figures 4 and 5 are defined by character states that are both widely recognised to vary among ritual architecture and can be applied to architecture from across Polynesia, two requirements for regional analysis. A previous analysis (Cochrane 2009), which omitted the Tuomotua 
data, but using the same or similar characters presented here, generated multiple cladistic trees from different taxa definitions and also concluded that similarities in Polynesian ritual architecture are most likely explained as a product of high levels of horizontal trait transmission or interaction, a finding similar to other quantitative cultural phylogenetic research in Polynesia and stone tool geochemical studies (Collerson and Weisler 2007, McAlister et al. 2013). Future research investigating cultural transmission and the similarities and differences of Polynesian ritual architecture should seek to develop architecture classifications to produce better resolved cladistic trees (i.e., trees with a greater number of bifurcations) as well as incorporate additional quantitative methods to explore phylogenetic relationships.

\section{ACKNOWLEDGEMENTS}

I thank the two anonymous reviewers for their careful reading and thoughtful engagement with the manuscript. The sharp eye of Melinda Allen also removed several errors and helped to make the presentation clearer. Their efforts greatly improved the work. I also thank Briar Sefton for Figure 1 and Thegn Ladefoged for Figure 6.

\section{REFERENCES}

Ackland, G.J., M. Signitzer, K. Stratford and M.H. Cohen, 2007. From the cover: Cultural hitchhiking on the wave of advance of beneficial technologies. Proceedings of the National Academy of Sciences USA 104: 8714-719.

Allen, M. S., 1996. Patterns of interaction in Southern Cook Islands prehistory. IndoPacific Prehistory Association Bulletin 15: 13-21.

Bellwood, P., 1975. The prehistory of Oceania. Current Anthropology 16: 9-28. 1978. The Polynesians: Ancient Peoples and Places. London: Thames and Hudson.

Bentley, R.A., M.W. Hahn and S. Shennan, 2004. Random drift and cultural change. Proceedings of the Royal Society of London 271: 1143-1450.

Bridgman, H.A., 1983. Could climatic change have had an influence on the Polynesian migrations? Palaeogeography, Palaeoclimatology, Palaeoecology 41: 193-206.

Buchanan, B. and M. Collard, 2008. Phenetics, cladistics, and the search for the Alaskan ancestors of the Paleoindians: A reassessment of relationships among the Clovis, Nenana, and Denali archaeological complexes. Journal of Archaeological Science 35: 1683-1694.

Cabioch, G., C.C. Wallace, M.T. McCulloch, H. Zibrowius, P. Laboute and B.R. de Forges, 2011. Disappearance of Acropora from the Marquesas (French Polynesia) during the last deglacial period. Coral Reefs 30: 1101-105.

Cochrane, Ethan E., 1998. Recent research and future advances in the analysis of Polynesian ceremonial architecture: A review essay. Asian Perspectives 37: 279-300. 
2001. Style, function, and systematic empiricism: The conflation of process and pattern. In T.D. Hurt and G.F.M. Rakita (eds), Style and Function: Conceptual Issues in Evolutionary Archaeology. Westport, Conn.: Bergin and Garvey, pp. 183-202.

-2008. Migration and cultural transmission: Investigating human movement as an explanation for Fijian ceramic change. In M.J. O’Brien (ed.), Cultural Transmission in Archaeology: Issues and Case Studies. Washington, D.C.: Society for American Archaeology Press, pp. 132-45.

2009. Cultural Relatedness of Polynesian Ritual Architecture. Paper presented at the Society for Hawaiian Archaeology Annual Meeting, Honolulu, Hawai'i. 2013. Quantitative phylogenetic analysis of Lapita decoration in Near and Remote Oceania. In G.R. Summerhayes and H. Buckley (eds), Pacific Archaeology: Documenting the Past 50,000 Years. Dunedin, University of Otago, pp. 17-42.

Cochrane, Ethan E. and Carl P. Lipo, 2010. Phylogenetic analyses of Lapita decoration do not support branching evolution or regional population structure during colonization of Remote Oceania. Philosophical Transactions of the Royal Society B: Biological Sciences 365 (1559): 3889-902.

Collard, M., S.J. Shennan and J.J. Tehrani, 2006. Branching, blending, and the evolution of cultural similarities and differences among human populations. Evolution and Human Behavior 27 (3): 169-84.

Collerson K.D. and M.I. Weisler, 2007. Stone adze compositions and the extent of ancient Polynesian voyaging and trade. Science 317: 1907-911.

Di Piazza, A. and E. Pearthree, 2004. Sailing Routes of Old Polynesia: The Prehistoric Discovery, Settlement and Abandonment of the Phoenix Islands. Honolulu: Bishop Museum Press.

Emory, K.P., 1928. Archaeology of Necker and Nihoa Islands. Honolulu: Bernice P. Bishop Museum.

-1933. Stone Remains in the Society Islands. Honolulu: Bernice P. Bishop Museum.

1934. Tuamotuan stone structures. Honolulu: Bernice P. Bishop Museum.

1970. A re-examination of East-Polynesian marae: Many marae later. In R.C. Green and M. Kelly (eds), Studies in Oceanic Culture History Volume 1. Honolulu: Bernice P. Bishop Museum, pp. 73-92.

Fitzhugh, B., 2001. Risk and invention in human technological evolution. Journal of Anthropological Archaeology 20: 125-67.

Fornander, A., 1969 [1878-1885]. An Account of the Polynesian Race, Its Origin and Migrations and the Ancient History of the Hawaiian People to the Times of Kamehameha I. Rutland, Vermont: Charles E. Tuttle Co.

Gray, R.D. and Q.D. Atkinson, 2003. Language-tree divergence times support the Anatolian theory of Indo-European origin. Nature 426: 435-38.

Greenhill, S.J., T.E. Currie and R.D. Gray, 2009. Does horizontal transmission invalidate cultural phylogenies? Proceedings of the Royal Society B: Biological Sciences 276 (1665): 2299-306.

Hunt, T.L., 2007. Rethinking Easter Island's ecological catastrophe. Journal of Archaeological Science 34 (3): 485-502. 
Kahn, J.G., 2010. A spatio-temporal analysis of 'Oro cult marae in the 'Opunohu Valley, Mo'orea, Society Islands. Archaeology in Oceania 45 (2): 103-10.

Kahn, J.G. and P.V. Kirch, 2011. Monumentality and the materialization of ideology in Central Eastern Polynesia. Archaeology in Oceania 46 (3): 93-104.

Kandler, A. and K.N. Laland, 2009. An investigation of the relationship between innovation and cultural diversity. Theoretical Population Biology 76: 59-67.

Kimbel, W.H., C.A. Lockwood, C.V. Ward, M.G. Leakey, Y. Rak and D.C. Johanson, 2006. Was Australopithecus anamensis ancestral to A. afarensis? A case of anagenesis in the hominin fossil record. Journal of Human Evolution 51: 134-52.

Kirch, P.V., 1984. The Evolution of the Polynesian Chiefdoms. Cambridge: Cambridge University Press.

-1990. Monumental architecture and power in Polynesian chiefdoms: A comparison of Tonga and Hawaii. World Archaeology 22: 206-22.

Kirch, P.V. and R.C. Green, 1987. History, phylogeny, and evolution in Polynesia. Current Anthropology 28: 431-56.

2001. Hawaiki, Ancestral Polynesia: An Essay in Historical Anthropology. Cambridge: Cambridge University Press.

Kitching, I.J., 1992. The determination of character polarity. In I.J. Kicthing, P.L. Forey, C.J. Humphries, and D.M. Williams (eds), Cladistics: A Practical Course in Systematics. Oxford: Claredon Press, pp. 22-43.

Kitching, I.J., P.L. Forey, C.J. Humphries, J. and D.M. Williams, 1998. Cladistics: The Theory and Practice of Parsimony Analysis. Oxford: Oxford University Press.

Kolb, M.J., 1994. Monumentality and the rise of religious authority in precontact Hawai'i Current Anthropology 34: 521-47.

Larsen, A.W., 2011. Evolution of Polynesian bark cloth and factors influencing cultural change. Journal of Anthropological Archaeology 30: 116-34.

Linton, R., 1925. The Archaeology of the Marquesas Islands. Honolulu: Bernice P. Bishop Museum.

Lipo, C.P., M.J. O'Brien, M. Collard and S. Shennan, 2006. Mapping Our Ancestors: Phylogenetic Methods in Anthropology and Prehistory. Piscataway, New Jersey: AldineTransaction.

Lyman, R.L., 2001. Culture historical and biological approaches to identifying homologous traits. In T. D. Hurt and G. F. M. Rakita (eds), Style and Function: Conceptual Issues in Evolutionary Archaeology. Westport, Conn.: Bergin and Garvey, pp. 69-90.

Lyman, R.L. and M.J. O'Brien, 2003. Cultural traits: Units of analysis in early twentieth-century anthropology. Journal of Anthropological Research 59: 225-50.

Mace, R., C.J. Holden and S. Shennan (eds), 2005. The Evolution of Cultural Diversity: A Phylogenetic Approach. London: UCL Press.

Martinsson-Wallin, H., 1994. Ahu - The Ceremonial Stone Structures of Easter Island: Analysis of Variation and Interpretation of Meanings. Aun Vol. 19. Uppsala: Societas Archaeologica Upsaliensis.

Martinsson-Wallin H., P. Wallin, A. Anderson and R. Solsvik, 2013. Chronogeographic variation in initial East Polynesian construction of monumental ceremonial sites. The Journal of Island and Coastal Archaeology 8 (3): 405-21. 
McAlister, A., P. Sheppard and M.S. Allen, 2013. The identification of a Marquesan adze in the Cook Islands. Journal of the Polynesian Society 122 (3): 257-73.

Mesoudi, A., 2011. Cultural Evolution: How Darwinian Theory Can Explain Human Culture \& Synthesize the Social Sciences. Chicago: University of Chicago Press.

Nunn, C.L., C. Arnold, L. Matthews and M.B. Mulder, 2010. Simulating trait evolution for cross-cultural comparison. Philosophical Transactions of the Royal Society B: Biological Sciences 365 (1559): 3807-819.

O’Brien, M.J., J. Darwent and R.L. Lyman, 2001. Cladistics is useful for reconstructing archaeological phylogenies: Palaeoindian points from the southeastern United States. Journal of Archaeological Science 28: 1115-136.

O’Brien, M.J., R.L. Lyman, Y. Saab, E. Saab, J. Darwent and D.S. Glover, 2002. Two issues in archaeological phylogenetics: Taxon construction and outgroup selection. Journal of Theoretical Biology 215 (2): 133-50.

Ormerod, P., 2005. Why Most Things Fail. London: Faber and Faber.

Rogers, D.S. and P.R. Ehrlich, 2008. Natural selection and cultural rates of change. Proceedings of the National Academy of Sciences USA 105: 3416-420.

Rogers, D.S., M.W. Feldman and P.R. Ehrlich, 2009. Inferring population histories using cultural data. Proceedings of the Royal Society B: Biological Sciences 276: 3835-843.

Rolett, B.V., 1998. Hanamiai: Prehistoric Colonization and Cultural Change in the Marquesas Islands (East Polynesia). New Haven, Conn.: Yale University. 2002. Voyaging and interaction in ancient East Polynesia. Asian Perspectives 41 (2): 182-94.

2010. Marquesan monumental architecture: Blurred boundaries in the distinction between religious and residential sites. Archaeology in Oceania 45 (2): 94-102.

Ross, R.M., S.J. Greenhill and Q.D. Atkinson, 2013. Population structure and cultural geography of a folktale in Europe. Proceedings of the Royal Society B 280: 20123065. http://dx.doi.org/10.1098/rspb.2012.3065

Scotland, R.W., 1992. Character coding. In P.L. Forey, C.J. Humphries, I.J. Kitching, R.W. Scotland, D.J. Siebert, and D.M. Williams (eds), Cladistics: A Practical Course in Systematics, Oxford: Claredon Press, pp. 14-21.

Sharp, W.D., J.G. Kahn, C.M. Polito and P.V. Kirch, 2010. Rapid evolution of ritual architecture in central Polynesia indicated by precise $230 \mathrm{Th} / \mathrm{U}$ coral dating. Proceedings of the National Academy of Sciences 107 (30): 13234-239.

Shennan, S., 2002. Genes, Memes, and Human History: Darwinian Archaeology and Cultural Evolution. London: Thames and Hudson.

Shennan, S.J., E.R. Crema and T. Kerig, (in press). Isolation-by-distance, homophily, and "core" vs. "package" cultural evolution models in Neolithic Europe. Evolution and Human Behavior.

Siebert, D.J., 1992. Tree statistics; trees and 'confidence'; consensus trees; alternatives to parsimony; character weighting; character conflict and its resolution. In P. L. Forey, C. J. Humphries, I. J. Kitching, R. W. Scotland, D. J. Siebert, and D. M. Williams (eds), Cladistics: A Practical Course in Systematics, Oxford: Claredon Press, pp. 72-88.

Skala, Z. and J. Zrzavy, 1994. Phylogenetic reticulations and cladistics: Discussion of methodological concepts. Cladistics 10 (3): 305. 
Spencer, M., E.A. Davidson, A.C. Barbrook and C.J. Howe, 2004. Phylogenetics of artificial manuscripts. Journal of Theoretical Biology 227 (4): 503-11.

Steele, J., 2009. Human dispersals: Mathematical models and the archaeological record. Human Biology 81: 121-40.

Stokes, J.F.G. and T.S. Dye, 1991. Heiau of the Island of Hawai ' $i$ : A Historic Survey of Native Hawaiian Temple Sites. Bishop Museum Bulletin in Anthropology, Volume 2. Honolulu: Bishop Museum Press.

Swofford, D.L., 2001. PAUP*: Phylogenetic Analysis Using Parsimony And Other Methods. Sunderland MA: Computer program distributed by Sinaur Associates.

Tehrani, J. and M. Collard, 2002. Investigating cultural evolution through biological phylogenetic analyses of Turkmen textiles. Journal of Anthropological Archaeology 21 (4): 443-63.

Teltser, P.A., 1995. Culture history, evolutionary theory, and frequency seriation. In P.A. Teltser (ed.), Evolutionary Archaeology: Methodological Issues. Tucson: University of Arizona Press, pp. 51-68.

Tolstoy, P., 2008. Barkcloth, Polynesia and Cladistics: An update. Journal of the Polynesian Society 117: 15-57.

Wallin, P., 1993. Ceremonial Stone Structures: The Archaeology and Ethnohistory of the Marae Complex in the Society Islands, French Polynesia. Aun vol. 18. Uppsala, Sweden: Societas Archaeologica Upsaliensis. 2001. "The Times They are A-Changing" or "Something is Happening Here" ... Some ideas on change in marae structures, Society Islands, French Polynesia. In C.M. Stevenson, G. Lee and F.J. Morin (eds), Pacific 2000: Proceedings of the Fifth International Conference on Easter Island and the Pacific. Los Osos, California: Easter Island Foundation, pp. 239-46.

Wallin P. and R. Solsvik, 2010. Marae reflections: On the evolution of stratified chiefdoms in the Leeward Society Islands. Archaeology in Oceania 45 (2): 86-93.

Weisler, M.I., 2004. Contraction of the southeast Polynesian interaction sphere and resource depression on Temoe Atoll. New Zealand Journal of Archaeology 25 [2003]: 57-88.

Weisler, M.I. and P.V. Kirch, 1996. Interisland and interarchipelago transfer of stone tools in prehistoric Polynesia. Proceedings of the National Academy of Sciences, 93 (4): 1381-85.

Wilmshurst, J.M., T.L. Hunt, C.P. Lipo and A.J. Anderson, 2011. High-precision radiocarbon dating shows recent and rapid initial human colonization of East Polynesia. Proceedings of the National Academy of Sciences 108 (5): 1815-20.

\section{ABSTRACT}

Ritual architecture across Polynesia displays similarities that are evidence of populations' shared ancestry and interaction. Examination of ritual architecture traitsthe design of courtyards, the use of uprights and sacrificial pits, the placement of walls and altars - has, for well over a century, contributed to hypotheses concerning the relatedness of different Polynesian groups and the transmission of ritual behaviours across islands and archipelagos. The research presented here follows this tradition 
and considers these traits from a quantitative phylogenetic perspective designed to generate hypotheses about the cultural relatedness of ritual architecture classes. Cladistics, a technique specifically designed to arrange classes into hierarchical patterns of relatedness, is presented and then used to construct cultural phylogenies of 198 pieces of ritual architecture from across East Polynesia. The cladistic analyses produce only very limited support for specific phylogenetic relationships between island and archipelago populations and instead suggest Polynesian ritual architectural variation is a product of both extensive horizontal cultural transmission or sharing and high levels of architectural trait innovation.

Keywords: Polynesia, ritual architecture, phylogeny, cultural transmission, Rapa Nui, Marquesas Islands, Society Islands

\section{CITATION AND AUTHOR CONTACT DETAILS}

Cochrane, ${ }^{1}$ Ethan E., 2015. Phylogenetic analysis of Polynesian ritual architecture suggests extensive cultural sharing and innovation. Journal of the Polynesian Society 124 (1): 7-46. DOI: http://dx.doi.org/10.15286/jps.124.1.7-46

${ }^{1}$ Corresponding author: Anthropology, University of Auckland, Private Bag 92019, Auckland 1142, New Zealand. E-mail: e.cochrane@auckland.ac.nz 